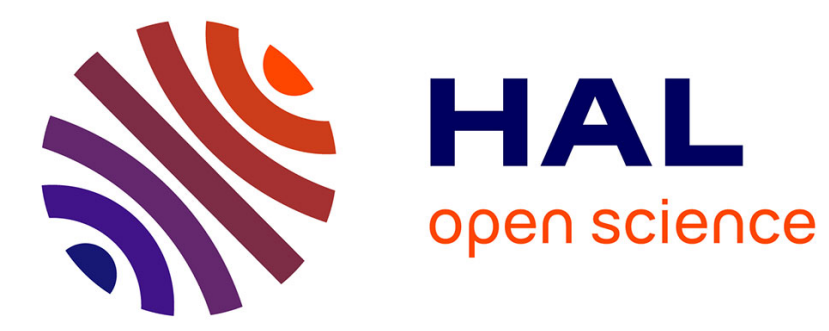

\title{
Migration in geographic and ecological space by a large herbivore
}

\author{
Wibke Peters, Mark Hebblewhite, Atle Mysterud, Derek Spitz, Stefano \\ Focardi, Ferdinando Urbano, Nicolas Morellet, Marco Heurich, Petter \\ Kjellander, John D.C. Linnell, et al.
}

\section{To cite this version:}

Wibke Peters, Mark Hebblewhite, Atle Mysterud, Derek Spitz, Stefano Focardi, et al.. Migration in geographic and ecological space by a large herbivore. Ecological monographs, 2017, 87 (2), pp.297-320. 10.1002/ecm.1250 . hal-01606181

\section{HAL Id: hal-01606181 \\ https://hal.science/hal-01606181}

Submitted on 26 May 2020

HAL is a multi-disciplinary open access archive for the deposit and dissemination of scientific research documents, whether they are published or not. The documents may come from teaching and research institutions in France or abroad, or from public or private research centers.
L'archive ouverte pluridisciplinaire HAL, est destinée au dépôt et à la diffusion de documents scientifiques de niveau recherche, publiés ou non, émanant des établissements d'enseignement et de recherche français ou étrangers, des laboratoires publics ou privés. 


\title{
Migration in geographic and ecological space by a large herbivore
}

\author{
Wibke Peters, ${ }^{1,2,3,12}$ Mark Hebblewhite, ${ }^{1}$ Atle Mysterud, ${ }^{3}$ Derek Spitz, ${ }^{1}$ Stefano Focardi, ${ }^{4}$ \\ Ferdinando Urbano, ${ }^{5}$ Nicolas Morellet, ${ }^{6}$ Marco Heurich, $,{ }^{7}, 8$ Petter Kuellander, ${ }^{9}$ \\ John D. C. Linnell, ${ }^{10}$ and Francesca CAGNACCI ${ }^{2,11}$ \\ ${ }^{1}$ Wildlife Biology Program, Department of Ecosystem and Conservation Sciences, University of Montana, Missoula, Montana 59812 USA \\ ${ }^{2}$ Biodiversity and Molecular Ecology Department, Research and Innovation Centre, Fondazione Edmund Mach, \\ Via Mach 1, 38010, San Michele all' Adige, TN, Italy \\ ${ }^{3}$ Department of Biosciences, Centre for Ecological and Evolutionary Synthesis, University of Oslo, \\ P.O. Box, 1066 Blindern, 0316 Oslo, Norway \\ ${ }^{4}$ Istituto Superiore per la Protezione e Ricerca Ambientale, Via Ca'Fornacetta 9, 40064 Ozzano dell'Emilia, BO, Italy \\ ${ }^{5}$ Freelance Eurodeer Database Manager, Via Nuoro 2, Milan, 20128 Italy \\ ${ }^{6}$ INRA UR35, Comportement et Écologie de la Faune Sauvage, Institut National de la Recherche Agronomique, \\ B.P. 52627, 31326 Castanet-Tolosan, France \\ ${ }^{7}$ Department of Conservation and Research, Bavarian Forest National Park, Freyunger Street 2, 94481 Grafenau, Germany \\ ${ }^{8}$ Wildlife Ecology and Management, Faculty of Environment and Natural Resources, University of Freiburg, Freiburg, Germany \\ ${ }^{9}$ Grimsö Wildlife Research Station, Department of Ecology, Swedish University of Agricultural Science (SLU), \\ 73091 Riddarhyttan, Sweden \\ ${ }^{10}$ Norwegian Institute for Nature Research (NINA), PO Box 5685 Sluppen, 7485 Trondheim, Norway \\ ${ }^{11}$ Organismic and Evolutionary Biology Department, Harvard University, 26 Oxford Street, Cambridge, Massachusetts 02138 USA
}

\begin{abstract}
Partial migration, when only part of the population migrates seasonally while the other part remains resident on the shared range, is the most common form of migration in ungulates. Migration is often defined by spatial separation of seasonal ranges and consequently, classification of individuals as migrants or residents is usually only based on geographic criteria. However, the underlying mechanism for migration is hypothesized to be movement in response to spatiotemporal resource variability and thus, migrants are assumed to travel an "ecological distance" (ED) or shift their realized ecological niches. While ecological and geographic distances should be related, their relationship may depend on landscape heterogeneity. Here, we tested the utility of ecological niche theory to both classify migratory individuals and to understand the underlying ecological factors for migratory behavior. We developed an integrative approach combining measures in geographic and ecological niche space and used this to classify and explain migratory behavior of 71 annual roe deer (Capreolus capreolus) movement trajectories in five European study areas. First, to assess the utility of the ED concept for classifying migratory behavior, we tested whether roe deer sought the same ecological conditions year-round or moved to different ecological conditions by measuring the annual ED travelled and the seasonal niche overlap using multivariate statistics. Comparing methods to classify migrants and residents based on geographic and ecological niche space, we found that migratory roe deer switched between seasons both in geographic and in ecological dimensions. Second, we tested which seasonal ecological factors separated resident from migrant niches using discriminant analysis and which broad-scale determinants (e.g., spatiotemporal forage variation and population density) predicted migration probability using generalized linear models. Our results indicated that factors describing forage and topographic variability discriminated seasonal migrant from resident niches. Determinants for predicting migration probability included the temporal variation (seasonality) and also the spatial variability of forage patches. Last, we also found suggestive evidence for a positive relationship between population density and migration probability. By applying the ecological niche concept to the study of partial migration in ungulates, our work underlines that partial migration is a form of behavioral plasticity.
\end{abstract}

Key words: behavioral plasticity; Capreolus capreolus; ecological distance; large herbivores; niche switching; Normalized Difference Vegetation Index; partial migration; realized niche; spatiotemporal variation; ungulates.

\section{INTRODUCTION}

Animal movement in response to resource gradients can take many forms (Müller and Fagan 2008). One

Manuscript received 17 January 2016; revised 21 November 2016; accepted 7 December 2016. Corresponding Editor: Madan K. Oli.

${ }^{12}$ E-mail: wibke.peters@ibv.uio.no much-studied movement behavior is migration, which is classically referred to as the seasonal movement of individuals from one region to another (Southwood 1962, Fryxell and Sinclair 1988, Dingle and Drake 2007). "Classic" round-trip migrations, such as the longdistance ones performed by songbirds that migrate between temperate and tropical zones, Serengeti wildebeest (Connochaetes taurinus) that follow green-up and 
escape limiting conditions, or pods of great whales migrating across oceans seeking more favorable birth sites, are the well-known type of migration. While many of these "classic" migrations take place across long distances, migration distances may vary by orders of magnitude even within taxa (Hein et al. 2012). Consequently, migration as a general phenomenon can neither be described by its distance nor the characteristics of its routes (Cagnacci et al. 2016). For example, in large herbivores, seasonal movement distances may vary greatly as a function of local spatiotemporal resource variability (Müller and Fagan 2008, Müller et al. 2011, Teitelbaum et al. 2015).

Despite being a well-known and common ecological phenomenon, there is currently no unifying consensus on how to describe and define migration (Dingle and Drake 2007, Cagnacci et al. 2011, Börger and Fryxell 2012). Nonetheless, two commonly acknowledged concepts seem to separate residency from migration. First, migration is defined by the spatial separation (i.e., allopatry) of seasonal ranges (Southwood 1962, Fryxell and Sinclair 1988, Dingle and Drake 2007). However, spatial separation is a descriptive geographic measure, and therefore does not explain the underlying ecological mechanisms, or motivations, for migration. Second, migratory behavior is hypothesized to occur in response to spatiotemporal resource variability (Fryxell and Sinclair 1988, Müller et al. 2011, Shaw and Couzin 2013). Differences in the spatial distribution of seasonal resources and their predictability are likely the main contributors to variation in seasonal movement (Fryxell et al. 2004, Müller et al. 2011). The study of migration has accordingly tended to focus first on whether migration occurs or not (the pattern), and then, second, on the determinants of migration (the processes; Cagnacci et al. 2016), without explicitly making the link between the two.

Partial migration, when only a portion of individuals within a population migrate, while the remainder stays resident either on the breeding or non-breeding range, is the most common form of migration. The phenomenon has been long recognized in temperate-zone birds (Lack 1943) and, more recently, in a wide range of species from other taxonomic groups including ungulates (e.g., Cagnacci et al. 2016), amphibians (Grayson and Wilbur 2009), and fish (Kerr et al. 2009). Ecological theory predicts that both movement tactics (migration and residency) will persist in the same population if the cost of migration is compensated by improved habitat quality in seasonal environments and if some form of density dependence exists (Taylor and Norris 2007). Partial migration should therefore be seen as a population level phenomenon (Taylor and Taylor 1977) that emerges as a consequence of individual behavior. Consequently, individual migratory status may be either obligate or facultative (Terrill and Able 1988). Specifically, individuals may adopt either a fixed strategy throughout their adult lives, usually resulting from genetic polymorphism (Lundberg 1988) or individuals can be plastic in their migratory behavior between years due to condition dependence or learned behavior via experience (Chapman et al. 2011a). Interestingly, strong evidence for genetic determinism for such migratory dimorphism is limited to date, especially for ungulates (Lundberg 1988, Barnowe-Meyer et al. 2013). Instead, research suggests that most animals display behavioral plasticity in migration "tendency" in response to spatiotemporal variability of resources (Cagnacci et al. 2011, Chapman et al. 2011b, Sih et al. 2012). For example, landscapes with very low spatial and temporal variation commonly support sedentary populations, while landscapes with high variability in space and time favor seasonal movements in the form of migration or nomadism in response to changes in resource distributions (Jonzén et al. 2011, Müller et al. 2011, Hein et al. 2012). With increasing seasonality and predictability, cue-driven migration, where animals migrate following seasonal stimuli, becomes more frequent (Sabine et al. 2002). In less predictable environments, facultative migration, where animals migrate only during certain years in response to environmental variation, may be expected (Nicholson et al. 1997, Sabine et al. 2002, Fieberg et al. 2008). Consequently, migration has also been viewed in the context of behavioral syndromes (Dingle and Drake 2007). For example, Olsson et al. (2006) found that brown trout (Salmo trutta) exhibited a flexible migratory tendency and local conditions had a strong impact upon individual decision making. Thus, one cause of confusion in the study of migration is that seasonal movement is very flexible and seldom fits well into two discrete categories of residency or migration, instead it occurs along a gradient between these two endpoints (Cagnacci et al. 2011). Partially migratory systems provide an ideal model system for studying migration, because of the explicit opportunity for comparisons of mechanisms driving the different individual migratory strategies (Chapman et al. 2011b).

Agreement on measuring or classifying migration has also not been achieved (McClintock et al. 2012). Consequently, classifying migratory behavior commonly depends on arbitrary rules that are often study specific. Furthermore, classifications of migratory behavior, such as the net squared displacement (NSD; Bunnefeld et al. 2011, Börger and Fryxell 2012, Singh et al. 2012), the degree of overlap between seasonal home ranges (Mysterud 1999, Ball et al. 2001, Fieberg and Kochanny 2005) or spatial clustering of seasonal locations (Cagnacci et al. 2011, 2016), are usually solely based on geographic space (the pattern). Uncertainty in geographic distance-based classification is often reported in animals that undertake multiple trips, have stop-over sites, do not stabilize in seasonal home ranges or undertake frequent excursions (Cagnacci et al. 2011, Mysterud et al. 2011, Bischof et al. 2012). Because changes of environmental conditions in space and time present the motivation to migrate (the determinants), definitions of migration based on geographic space alone are incomplete to understand the 
underlying processes of migration (Cagnacci et al. 2011). Although several authors have emphasized that migration involves moving between different habitats (occupy different realized ecological niches), this concept has not been used to measure, describe or define migratory vs. nonmigratory states (Jonzén et al. 2011).

Distances between seasonal ranges of migrants have been commonly considered in geographic space, including horizontal and altitudinal distances, but rarely in environmental space as ecological distances (ED) traveled (LeResche 1974). The concept of the "ecological distance" suggests that migratory movements should involve a change in environment between seasons to be adaptive. This implies that migratory behavior may not solely be described using geographic measures, but also in terms of the switch from one environment to another. For example, very short distance migrations in heterogeneous landscapes may not be detectable with geographic classification measures, but migrants may accomplish large environmental changes similar to migrations across long geographic distances in homogenous landscapes (Fig. 1; Edwards and Ritcey 1956, White et al. 2014). Such short geographic distance migrations are typically altitudinal migrations that result in changes in microclimate (Shaw and Couzin 2013) and have been documented for Neotropical birds (Boyle 2011) or Sierra Nevada bighorn sheep (Ovis canadensis sierrae, Spitz et al. 2016). Interestingly, such short distance movements have fueled discussions on whether to actually consider them migrations and arbitrary thresholds have often been applied. For example, Mysterud et al. (2011) and Bischof et al. (2012) considered migratory movements in red deer only if the distance between seasonal ranges exceeded $3000 \mathrm{~m}$. In contrast in very homogenous, often flat, landscapes migrants must move long geographic distances to achieve significant environmental changes. Such migrations are typical for tundra dwelling populations of caribou (Rangifer tarandus; Bergman et al. 2000). Consequently, under extreme circumstances, depending on the landscape, individuals may occupy non-overlapping seasonal ranges with similar ecological niche conditions. In contrast, in a sufficiently heterogeneous landscape, individuals may even have geographically adjacent or even partly overlapping seasonal ranges, yet including widely different ecological niche conditions. Thus, the relationship between the environmental distances travelled and the associated geographic distances will ultimately be a function of the spatial heterogeneity of the habitat an individual occupies. A framework explicitly addressing both geographic and ED is important to enhance our understanding of migration.

Ecological niche theory predicts that different species thrive within specific ranges of environmental conditions in distinct geographic ranges (Hutchinson 1957). The fundamental niche encompasses all $n$-dimensional combinations of abiotic factors in which a species can persist without immigration (Soberón 2007), while the realized niche represents the proportion that is actually occupied by a species in the presence of biotic factors, such as predation and inter- or intraspecific competition (Hirzel and Le Lay 2008). Consequently, density dependence is not only a common determinant for migration, but is also a major biotic determinant for limiting the realized niche within the fundamental niche space (Soberón and Nakamura 2009). Interestingly, it is often assumed that migrants change ecological conditions, but migration may also be linked to social factors related to aggregation in seasonal groups not necessarily requiring a seasonal switch of habitat (Wahlström and Liberg 1995). While it has been tested whether particular ecological factors,
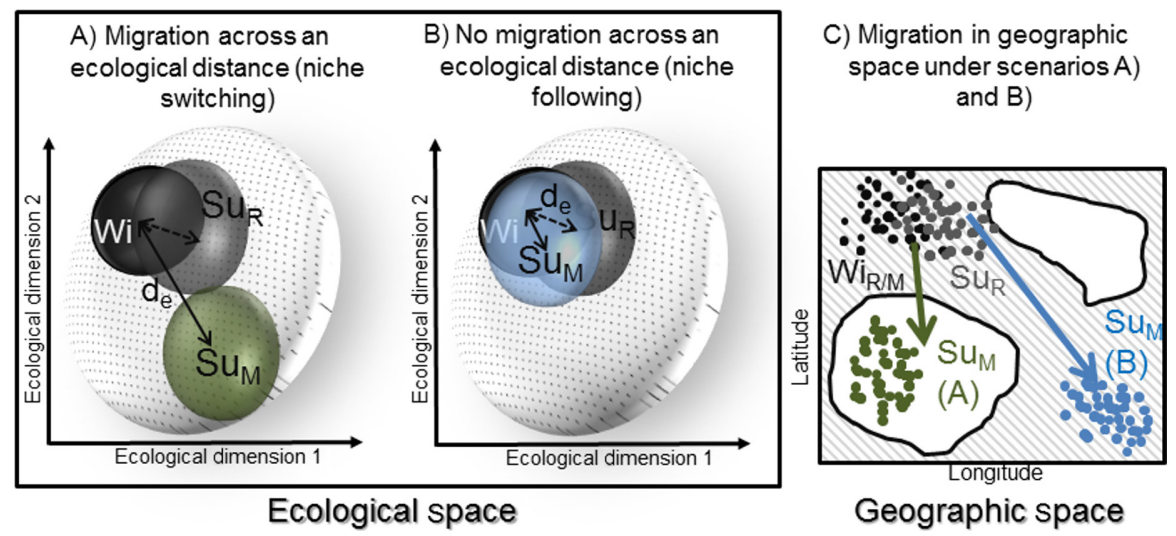

FIG. 1. Conceptual representation of the hypothesized relationship between the ecological distance and seasonal niche overlap under two hypotheses; (A) seasonal niche switching by migrant (M) animals and (B) seasonal niche following by migrant animals. Due to the aim of classifying migration (Objective 1), residents (R) are assumed to be conservative in their seasonal niches (always follow their seasonal niches). The light gray area in panels A and B represents the fundamental niche of the species and the dark or colored areas represent the realized seasonal niches, where migrants that switch niches are displayed in green, migrants that follow niches are displayed in blue and resident summer (Su) niches are dark gray. Shared winter (Wi) niches of both residents and migrants are displayed in black. (C) Distribution of the realized seasonal niches in geographic space, where residents maintain winter and summer ranges with high spatial overlap in close proximity. While migrants always move Cartesian distances between summer and winter ranges, they may switch to different habitats (A; niche switching) or move to similar habitats (B; niche following). 
such as elevation or distance to coast (Mysterud et al. 2011), differ between winter and summer ranges of migrants, a coherent framework encompassing a wide range of ecological factors has rarely been explored. The dimensions of the realized niche can be estimated by measuring ecological conditions at geographic locations where animals are present. The geographic space inhabited by an organism depends on the distribution of ecological conditions in space and time (Pulliam 2000), but movement defines which geographic areas are accessible, thus, further restricting realized habitat (Soberón 2007). Through the lens of accessibility, movement consequently plays a critical role in determining the dimension of the ecological niche (Soberón 2007). Furthermore, migration provides an excellent example of variation in the realized niche in time (Jonzén et al. 2011). Differential movement between geographically distinct "niches" over time can be a critical component shaping the spatial distribution of species, populations and individuals (Soberón 2007, Soberón and Nakamura 2009).

The extent to which migratory individuals occupy similar niches throughout the year, indicating the ED travelled, remains a fundamental question in migration studies (Jonzén et al. 2011). Interestingly, in Neotropical birds, climatic niche followers, which travel no ED, and niche switchers, which travel across EDs, have been found in both residents and migrants (Nakazawa et al. 2004, Laube et al. 2015, Gómez et al. 2016). In contrast, it may be unlikely for terrestrial migrants in seasonal temperate environments, such as large herbivores, to follow seasonal niches, because they are commonly restricted to their climatic zones due to locomotive constraints. In this case, the geographic distance an individual has to migrate to achieve an ecological displacement may be a function of the spatiotemporal landscape heterogeneity (Shaw and Couzin 2013). However, under the paradigm of adaptability, one expects changes in the realized niche of migrants offering increased access to fitness-enhancing factors, such as forage or reproduction, and avoidance of fitness-decreasing factors, such as predation risk or intraor interspecific competition (Avgar et al. 2013). Understanding to what degree migrants travel EDs, as well as how geographic distances to achieve those EDs may vary in landscapes with different configurations may aid in understanding ecological constraints on migration. Yet, such relationships remain untested for any taxonomic groups apart from birds (Nakazawa et al. 2004, Jonzén et al. 2011, Laube et al. 2015, Gómez et al. 2016).

Large herbivores represent an ideal taxonomic group of high ecological and economic importance (Hobbs 1996, Gordon et al. 2004) to study variation in migratory behavior, especially because many migratory species are partially migratory, including impalas (Aepyceros melampus; Gaidet and Lecomte 2013), African buffalo (Syncerus caffer; Naidoo et al. 2012), Serengeti wildebeest (Fryxell and Sinclair 1988), moose (Alces alces; Ball et al. 2001), pronghorn (Antilocapra americana, White et al. 2007), red deer (Cervus elaphus elaphus; Mysterud et al. 2011), elk (Cervus elaphus canadensis; Hebblewhite et al. 2008), white-tailed deer (Odocoileus virginianus; Grovenburg et al. 2011), and roe deer (Capreolus capreolus; Cagnacciet al. 2011, Mysterud 1999). Ungulate migration has been suggested to be flexible, and individuals can show variation in migratory behavior from year to year due to condition dependence in a facultative manner (Nelson 1995, Fieberg et al. 2008, Grovenburg et al. 2011). For large herbivores, migratory movements are commonly undertaken in response to spatiotemporal forage patterns (Fryxell 1991). Specifically, the forage maturation hypothesis $(\mathrm{FMH})$ predicts that migrants benefit from adaptive spring movements across EDs to gain prolonged access to high-quality forage on summer ranges (Fryxell and Sinclair 1988, Hebblewhite et al. 2008), and to reduce predation risk (Fryxell and Sinclair 1988) or parasite loads (Folstad et al. 1991, Mysterud et al. 2016). Return migrations to lower elevations from summer to winter ranges are mainly related to avoiding adverse weather conditions depleting forage resources and restricting movements (Cagnacci et al. 2011). In general, landscapes that show very little broad-scale variation and low levels of seasonality in habitat suitability should support sedentary populations, while landscapes that vary across broad scales, and are seasonally predictable should favor migration (Jonzén et al. 2011, Müller et al. 2011, Hein et al. 2012). Because forage intake is often also a function of local herbivore density, migration is commonly viewed as a strategy to reduce density-dependent competition for forage by migrating away from over-utilized shared seasonal ranges (Fryxell and Sinclair 1988, Mysterud et al. 2011, Middleton et al. 2013, Hopcraft et al. 2014). The costs of migration can be balanced by migrating to alternate high quality habitat (Taylor and Taylor 1977). For example, Mysterud et al. (2011) and Eggeman et al. (2016) tested the competition avoidance hypothesis in Norway and Canada, respectively, and showed that variability in ungulate migration was related to density. Another study by Nelson (1995) indicated that white-tailed deer limited the time spent on shared winter ranges due to density dependent competition. Thus, extrinsic ecological gradients in forage and risk, and intrinsic gradients in density itself, comprising spatiotemporal variability in the realized ecological niche, are likely to explain partially migratory behavior in large herbivores (Fryxell and Sinclair 1988).

The overall twin objectives of our paper are to test the efficacy of the ED concept (LeResche 1974) to first, serve as a framework for describing/measuring (patterns) and to second, assess and explain the mechanisms (determinants) of migration in a large herbivore species with high behavioral plasticity (see Fig. 2 for a conceptual outline; Cagnacci et al. 2011). We evaluated the ED concept using individual animal movement data from five study areas from one of the most common ungulate species with a wide distribution in Europe, the European roe deer (Melis et al. 2009). Roe deer occupy a broad range of habitats from northern Scandinavian boreal forests to 


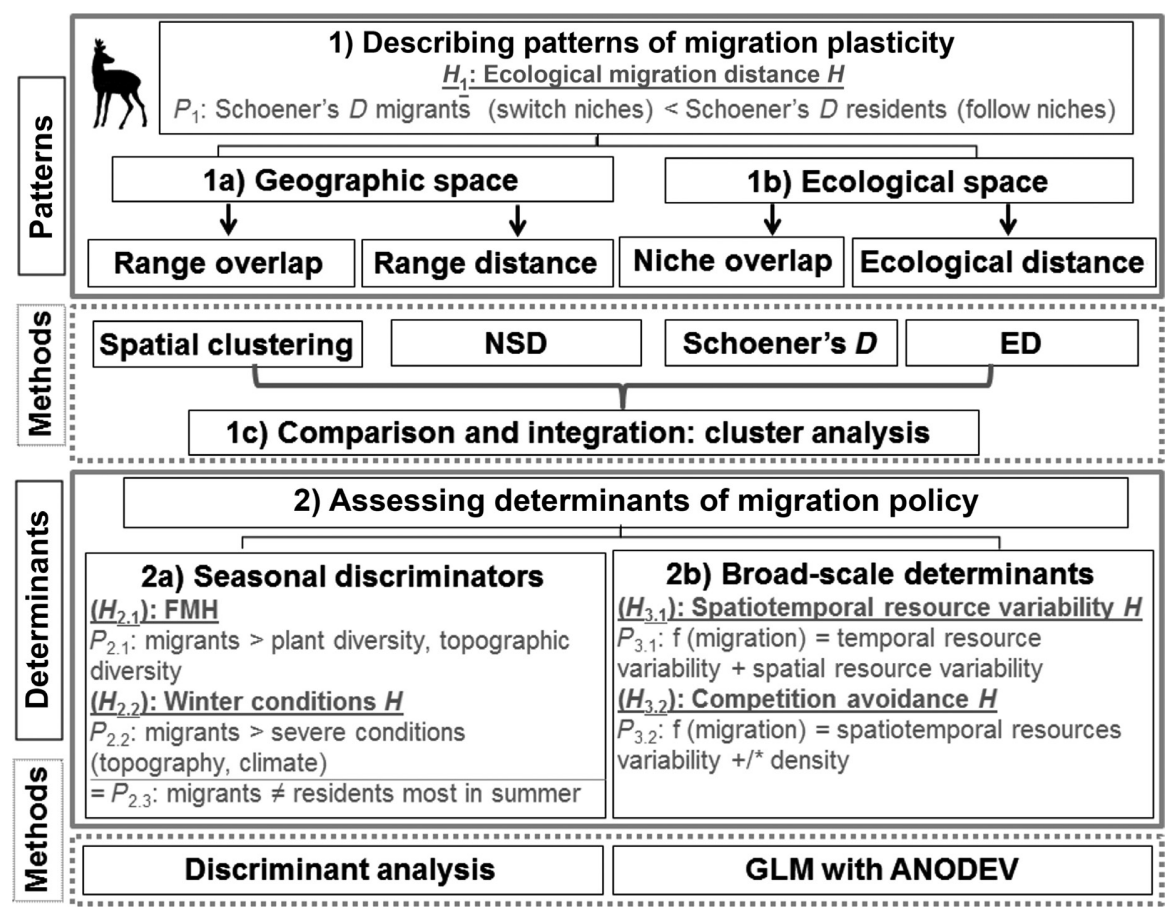

FIG. 2. Conceptual figure of workflow to study plasticity in migratory behavior in a small ungulate, the European roe deer (Capreolus capreolus), across five European study areas using Global Positioning System (GPS) movement data collected between 2005 and 2013. Each set of numbered objectives is followed by the predicted relationships (P) under specific hypotheses (H) and methods used to address them. Other abbreviations used in the figure: FMH, forage maturation hypothesis; NSD, net squared displacement; Schoener's D, Schoener's niche overlap; ED, ecological distance; GLM, generalized linear models; ANODEV, analysis of deviance.

Mediterranean chaparral environments (Linnell et al. 1998). Roe deer alternate between two main behavioral and physiological seasons annually: the reproductive season in spring and summer, when this species is mainly solitary and territorial, and the winter season, when small family groups can be observed (Hewison et al. 1998). It should be noted that, in contrast to all other temperate zone ungulates, roe deer mate during summer rather than autumn. A wide range of seasonal movement patterns have been documented within populations with intermediate-distance migrations in northern environments (Wahlström and Liberg 1995, Mysterud 1999) and short distance migrations in the Alps (Ramanzin et al. 2007). Cagnacci et al. (2011) found individual-level differences in migration probability and distance as a function of winter severity and topography resulting in different proportions of migrants across Europe. Because roe deer display a high level of behavioral plasticity (Cagnacci et al. 2011), and many populations are partially migratory, roe deer are an ideal model species for the study of migration.

Keeping in mind our twin objectives to describe (Fig. 2, Objective 1; Patterns) and explain (Fig. 2, Objective 2; Determinants) migratory behavior in this large herbivore, we tested a set of three hypotheses. First, we assessed the patterns of migration using geographic and ecological migration measures (Fig. 2, Objective 1;
Patterns) and evaluated the hypothesis that terrestrial ungulate migration entails a shift in ecological niche space (niche switching) or that migrants travel an ED ( $H_{1}$, the ecological migration distance hypothesis; Figs. 1, 2) when moving in geographic space. While we expected that all roe deer would switch seasonal niches to some degree (e.g., due to seasonal range expansion/contraction), under the ecological migration distance hypothesis $\left(H_{1}\right)$ we predicted that $\left(P_{1}\right)$ seasonal realized ED and niche overlap should follow a gradient from residency to migration (i.e., seasonal niches should overlap least for migrant and most for resident roe deer). If we could confirm the key assumption that roe deer migrate not only in geographic space (Fig. 2, Objective 1a; Geographic space), but also in ecological space (LeResche 1974, Fig. 1, Objective 1b; Ecological space), we wanted to evaluate if the mechanistic changes can be combined with geographic classification parameters to define migration for roe deer (i.e., describe the patterns and measuring migration, Fig. 2, Objective 1c; Comparison and integration). Thus, while previous attempts to describe or classify migration and residency relied solely on various measurements of geographic distance (Cagnacci et al. 2016), here we compare measures derived in both geographic space and ecological niche space in an integrative framework to classify individual roe deer into groups according to their migration tendency. 
To address the second part of our twin objectives, we tested which ecological factors explained the differences in seasonal niches between our migratory classifications (Fig. 2, Objective 2a; Seasonal discriminators). To do so, we estimated seasonal differences in ecological niche space by sampling parts of the $n$-dimensional hypervolume (Hutchinson 1957) including climatic, topographic and forage parameters at animal occurrence locations (Hirzel and Le Lay 2008) to test for predictions derived under the forage maturation hypothesis $\left(H_{2.1}\right)$. We expected that $\left(P_{2,1}\right)$ variables describing migrant summer niches would be correlated with variables that can be associated with forage productivity (Hebblewhite et al. 2008, Bischof et al. 2012), including variability in vegetation or topography that may act as proxies for higher phenological plant diversity (Albon and Langvatn 1992, Mysterud 1999, Cagnacci et al. 2011). For example, altitudinal gradients affect snowmelt and thereby the start of plant growth (Walker et al. 1993). Consequently, in ranges with high topographic diversity, including steeper slopes, herbivores can take advantage of highquality forage for extended time periods (Reitan 1988) due to the diversity of solar radiation exposure, moisture, soil types and delayed forage green-up. Unlike many other temperate ungulates, roe deer are income-breeders, which means that especially during the reproductive season from early to late summer (birth and mating) they need to continuously ingest high quality forage. Because they are small-bodied concentrate selectors, phenological diversity of nutritious plants rather than quantity is especially important. Next, under the winter conditions hypothesis $\left(H_{2.2}\right)$ we predicted that $\left(P_{2.2}\right)$ especially migratory roe deer summer ranges should be correlated with severe winter conditions that exclude winter occupancy by roe deer. Under both, the forage maturation hypothesis and the winter conditions hypothesis, we last predicted that $\left(P_{2.3}\right)$ the niches of residents and migrants should differ most in summer, the migratory season for partially migratory roe deer.

Last, we tested two main hypotheses for migration probability using factors that act at larger spatiotemporal scales, e.g., the level of the study area (Fig. 2, Objective $2 \mathrm{~b}$; Broad-scale determinants), which suggest that migration is dependent on spatiotemporal variation in resource availability $\left(H_{3.1}\right.$, the spatiotemporal resource variability hypothesis) and density $\left(H_{3.2}\right.$, the competition avoidance hypothesis). Specifically, under the spatiotemporal resource variability hypothesis $\left(H_{3.1}\right)$ we predicted that $\left(P_{3.1}\right)$ the probability of migration in roe deer would be higher in more seasonal landscapes and that increased broad-scale spatial heterogeneity of seasonal forage resources should increase the probability of migratory behavior (Müller et al. 2011, Shaw and Couzin 2013). Under the competition avoidance hypothesis $\left(H_{3.2}\right)$ we predicted that $\left(P_{3.2}\right)$ spatiotemporal variability in forage availability may be modulated by density and we expected an overall higher probability of migration with increasing densities (Eggeman et al. 2016).

\section{Methods}

\section{Study areas and animal location data}

We used 71 global positioning system (GPS) trajectories from adult roe deer in five European populations (28 trajectories from males and 43 from females) collected between 2005 and 2013 (Appendix S1: Table S1) maintained by the collaborative Eurodeer project (data available online; Fig. 3). ${ }^{13}$ We considered an analysis year ("migration trajectory") to begin 1 January of year 1 and end 31 March the following calendar year and included only trajectories that had enough daily location data that allowed reliable identification of space use patterns $(\sim 80 \%)$. In total we used data from 64 individual roe deer of which seven had trajectories for two years. Because facultative migration is common in roe deer, individual migration status was allowed to vary between years and covariates were also migration-year-specific. We did not include roe deer less than one year old, which may show natal-dispersal behavior that could confound our analyses (Cagnacci et al. 2011). Our study areas included populations in Rendena, Italy ( $n=7$, IT.1), Bondone, Italy ( $n=11$, IT.2), Bavarian Forest, Germany and Czech Republic ( $n=26, \mathrm{DE} / \mathrm{CZ})$, Koberg, Sweden $(n=14, \mathrm{SE})$ and southern Norway $(n=13, \mathrm{NO})$. Roe deer in these populations are partially migratory, with the highest migration probabilities in the Alpine and Norwegian roe deer populations and very low to no migration probabilities in the Swedish population (Cagnacci et al. 2011). Animals were captured either with box traps or drive nets (Peterson et al. 2003) according to local experimental animal care regulations approved for each respective Eurodeer member group. The GPS data sampling interval ranged between 1 and 12 locations/day. Because the sampling interval differed within and between populations and we were primarily interested in seasonal movement and broad niche patterns we reduced and standardized all animal location data to one daily location.

\section{Objective 1: Describing patterns of migration plasticity}

Objective 1a: Describing migration plasticity in geographic space. - To test the ecological migration distance hypothesis $\left(H_{1}\right)$, we estimated geographic and ecological migration measures using roe deer GPS data. We first classified migratory behavior in geographic space (Fig. 2, Objective 1a; Geographic space) using two established geographic pattern-based methods (Cagnacci et al. 2016). First, we used a spatially explicit method that describes the outcome of the movement process by measuring the spatiotemporal overlap of seasonal animal locations (Cagnacci et al. 2011). We applied a supervised clustering procedure (SAS 9.2, PROC CLUSTER: SAS Institute Inc., Cary, NC, USA) developed by Cagnacci et al. (2011) to identify the two main non-overlapping location clusters with range residency of at least one

\footnotetext{
${ }^{13}$ www.eurodeer.org
} 


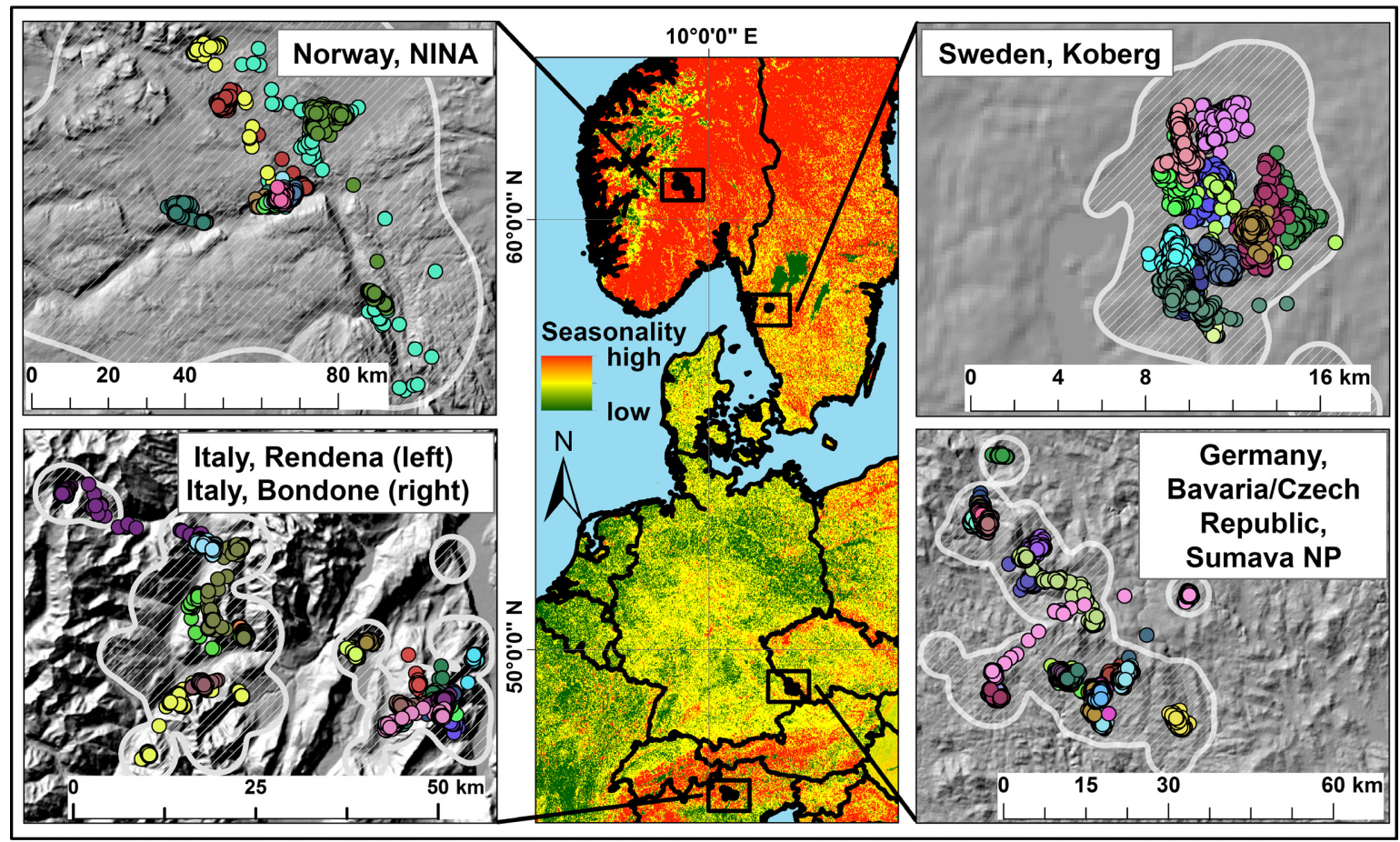

FIG. 3. GPS collar data of 71 annual roe deer (Capreolus capreolus) trajectories that were collected between 2005 and 2013 in five European study areas. The gray-shaded polygons represent study area extends $(95 \%$ kernels) and colored points represent individual animal location data. The background in the center map shows seasonality of vegetation measured as contingency (Colwell 1974) of the Normalized Difference Vegetation Index across a time series from 2001 to 2012. NP, National Park.

month by individual roe deer (herein, the spatial clustering method). This approach differentiates between residents vs. non-residents, which include all movement types with more than one range throughout the year (Cagnacci et al. 2011). Migration distance was estimated with the geographic distance $(\mathrm{km})$ between the centers of the seasonal location clusters.

The second geographic pattern-based method was the NSD method (Bunnefeld et al. 2011). This method applies competing non-linear models to the NSD of an animal movement trajectory. The competing models represent different seasonal movement tactics including residency, migration, mixed migration, nomadism, and dispersal. The resident model describes a more or less stable annual range. The migration model describes seasonal movements between one winter and one summer range with a return migration to the same winter range, while the mixed migration model describes a return migration not to the exact same winter range, but to a nearby area. The nomadism model suggests continuously increasing movements relative to the starting location, while the dispersal model described movements away from the initial range and settling in a new area (for more details see Bunnefeld et al. 2011). The best model was chosen based on the Akaike information criterion (AIC; Burnham and Anderson 2004). If more complex models were within two AIC points of each other we concluded that the additional parameters were uninformative and chose the simpler model (Arnold 2010). We excluded nomadism, because it is the movement type that is most commonly misclassified by this method (Bunnefeld et al. 2011). The distance between different seasonal locations was given by the asymptotic height of the top model ( $\delta$ ). For resident behavior $\delta$ remains approximately constant throughout the year, representing the average squareroot-transformed diameter of the home-range (Turchin 1998), while for migrants, $\delta$ represents the square-roottransformed migration distance. NSD analyses were conducted in R 3.2.1 (R Development Core Team 2013) using the migrateR package (Spitz 2015). We considered seasonal movements to be migration if residence time was at least $30 \mathrm{~d}$ on either seasonal range for both geographic methods to avoid misclassification of commuters (Cagnacci et al. 2011).

Objective 1b: Describing migration plasticity in ecological space.-Next, we described and measured process-based migration plasticity in ecological niche space (Fig. 2, Objective 1b; Ecological space). Because ecological niche variables are often correlated (e.g., forage quality and elevation), combining their effects in a generalized linear modeling framework is often statistically challenging (Hirzel and Le Lay 2008). Therefore, we took advantage of multivariate approaches that allowed inclusion of multiple competing factors to explain ungulate movements, approximating the idea of the $n$-dimensional hypervol- 
ume (Fig. 2; Hutchinson 1957). We first estimated the separation of seasonal ecological niches using Schoener's $D$ (Schoener 1974), which is conceptually the processbased equivalent to the pattern-based spatial separation of animal geographic location clusters estimated (Fig. 2, Spatial clustering). This measure also allowed us to test for ecological separation between seasonal niches of migratory roe deer (Fig. 2).

We estimated niche overlap for each roe deer between winter (January-March) and summer (June-August) based on methods described by Broennimann et al. (2012). We first applied kernel smoothers to densities of animal locations and associated environmental variables (see Identification and definition of ecological niche variables, and Appendix S2: Table S1 for details) collected in geographic space to estimate Schoener's (realized) niche overlap $(D)$ in multivariate environmental space. Kernel smoothers were estimated in a gridded environmental space (i.e., where each cell corresponds to a unique set of environmental conditions) as a function of the observed variables at animal locations from both seasonal ranges. We then calculated the density of occurrences and their associated environmental factors along the environmental axes of a multivariate Hill and Smith Analysis (Chessel et al. 2004). The Hill and Smith method allows for the incorporation of continuous and categorical environmental variables to represent the $n$-dimensional ecological realized niche space. Then, we measured niche overlap along the gradients of this multivariate analysis. Kernel density functions (Gaussian kernel with a standard bandwidth; Silverman 1986) were used to determine the "smoothed" density of occurrences in each cell in the environmental space for each animal. Environmental variables of animal locations from both seasons were used to calibrate the environmental space. Then, we measured niche overlap between the two seasonal ranges on the location values in the summer and winter grids. Using the occupancy of each environmental grid cell, scaled between 0 and 1 , we finally calculated niche overlap using the $D$-metric (Schoener 1974). A $D$-metric value of 1 indicates high seasonal niche overlap (or niche tracking), while a value of 0 indicates low seasonal niche overlap (or niche switching; Fig. 2). For this analysis we used R code provided by Broennimann et al. (2012).

Next, because we wanted to track individual roe deer in annual ecological niche space using static niche variables, we measured ED throughout the year, which is conceptually comparable to the NSD method in geographic space (Fig. 2). Specifically, we estimated the ED between consecutive daily locations of individual roe deer, that is, the ecological realized niche of each individual through time. To achieve this, we sampled environmental variables at animal locations (see Identification and definition of ecological niche variables) and applied a multivariate Hill and Smith Analysis to these location data for each individual separately. All variables were centered and normed and we selected the number of axis for each analysis by visually examining scree plots for an "elbow effect" to determine the number of axes to retain in the analysis (Jongman et al. 1995). Because we wanted to maximize differences between consecutive time periods to estimate the EDs roe deer travel, we used a Between-Class Analysis (BCA) based on the Hill-Smith standardized scores (Doledec and Chessel 1987). The BCA requires one instrumental variable between which the variances are maximized, and we included month as a factor. For each individual, we measured the multivariate niche positions of all animal locations (i.e., the row coordinates from the BCA), centered on the first observation for an animal of the year considered. This allowed us to track the movements in ecological niche space as a function of the environmental variables considered. Next, we extracted different parameters from these ecological niche trajectories.

We plotted the coordinates of BCA axes 1 and 2, which allowed us to treat them as coordinate data in niche space. Using the same methods that we used to estimate NSD following Bunnefeld et al. (2011), we fitted nonlinear models to these ecological niche trajectories and selected the model with the best fit based on AIC. Similar to the way that we measured Cartesian migration distance using the geographic NSD method, we estimated the ED of seasonal movements by individual roe deer by the asymptotic height of the top model $(\delta)$. Because migration may be described best by a variety of different measures (Cagnacci et al. 2016) of ED, we derived several parameters, including the relative change in ecological niche distance (change in ecological niche position) between the first location (i.e., ED of 0) and the average of the summer months (June, July, August; herein $\left.\mathrm{ED}_{\text {wi-su }}\right)$ and the standard deviation during the summer $\left(\mathrm{ED}_{\mathrm{SD}}\right.$; a measure of seasonal niche stability).

Objective 1c: Comparison and integration: toward a combined approach for the classification of migratory behavior-Upon estimation of migration parameters in geographic space (Fig. 2, Objective 1a; Geographic space) and ecological niche space (Fig. 2, Objective 1b; Ecological space), we compared geographic distance ( $\mathrm{km}$ migrated) and ED (niche overlap $D$ ) for each individual and tested this relationship in each study area characterized by different landscape heterogeneity under the ecological migration distance hypothesis $\left(H_{1}\right)$. Next, as a final component of our first objective to describe patterns of migration plasticity for roe deer, we compared geographic and ecological classification approaches separately using a Kappa statistic. The Kappa statistic has been used to evaluate the agreement between two categorical datasets. A Kappa index value of 1 indicates perfect agreement, while a value of 0 indicates that the observed agreement was approximately equal to what would be expected by chance (Cohen 1960). Finally, we combined all classification measures in an integrative approach to classify roe deer migratory behavior (Fig. 2, Objective 1c; Comparison and integration). Specifically, we used $k$-means cluster analysis to compare how much variation was explained in classifying seasonal movements by roe 
deer by the three classification systems; geographic space, ecological niche space, and the integrative approach. For geographic space, we performed cluster analysis on the distance between seasonal geographic clusters, the $\delta$ of the NSD, and the categorical classification from each geographic method (resident or non-migrant for the spatial clustering method and four categories defined by NSD: migrant, resident, mixed migrant, dispersal). For ecological space, we included the $\delta$ of the ED, the niche overlap $(D)$, the $\mathrm{ED}_{\text {wi-su }}$, the $\mathrm{ED}_{\mathrm{SD}}$, and the four categories defined by ED (migrant, resident, mixed migrant, dispersal) in the $k$-means cluster analysis. For our integrative classification approach we conducted a $k$-means cluster analysis on all geographic and ecological measures combined. For each combination of measures we created a dissimilarity matrix between the observations using Gower's Distance (Gower 1971), allowing us to include categorical and continues variables. For each approach, geographic, ecological and integrative, we estimated the natural number of clusters using the optimum average silhouette width (Rousseeuw 1987). The silhouette describes the tightness and separation of the data points within a cluster. The average silhouette width $(\bar{S}(k))$ of all clusters provides an evaluation of the clustering validity and can be used to define the number of clusters maximizing separation. Cluster analyses were conducted using the R package cluster (Maechler et al. 2015).

\section{Objective 2: Assessing determinants of migration plasticity}

Objective 2a: Determinants underlying seasonal roe deer niches.-Using the classification of the integrative approach (see Results) developed in Objective 1, we next tested our hypotheses regarding the determinants of migration plasticity (Fig. 2, Objective 2; Determinants) to assess general discriminators of seasonal niches of different movement tactics (Fig. 2, Objective 2a; Seasonal discriminators) and broad-scale determinants of the probability of migration across study areas (Fig. 2, Objective 2b; Broad-scale determinants). We used canonical discriminant analysis (DA) in R-package ade4 (Chessel et al. 2004) to test the predictions under the forage maturation hypothesis $\left(H_{2.1}\right)$ and the winter conditions hypothesis $\left(H_{2.2}\right)$ that a combination of forage, topography, and climate separate realized ecological niches of roe deer with different seasonal movement strategies (Fig. 2, Objective 2a; Seasonal discriminators). We averaged a suite of standardized (centered and normed) environmental variables (see Identification and definition of ecological niche variables; Appendix S2: Table S1) measured at GPS locations of individual roe deer for winter (January-March) and summer (June-August). We used Monte Carlo permutation tests to assess the statistical significance of the DA (999 permutations, $\alpha=0.05$; ter Braak 1992). Finally, we produced a biplot of the different groups of migration strategies and seasons and environmental variables in realized ecological niche space and reported canonical coefficients (CC) to assess the influence of environmental variables in discriminating the groups.

Objective 2b: Broad-scale determinates of migratory probability.-Last, to test if migration probability was a function of broad spatiotemporal variability in forage resources $\left(P_{3.1}\right)$ under the spatiotemporal resource variability hypothesis $\left(H_{3.1}\right.$; Müller et al. 2011), and possibly modulated by roe deer density $\left(P_{3.2}\right)$ under the competition avoidance hypothesis $\left(H_{3.2}\right.$; Mysterud et al. 2011) we used generalized linear models (GLM; Fig. 2, Objective 2b; Broad-scale determinants). Specifically, we tested if regions with lower spatiotemporal resource variation have lower probabilities of migration and if migratory probability increases at higher densities. To characterize this long-term and broad-scale spatiotemporal variability we retained the mean of contingency (seasonality), constancy (inter-annual variability) and the sum of contingency and constancy (predictability) as measures of temporal variation (Colwell 1974) per individual roe deer trajectory. To characterize spatiotemporal variation, or heterogeneity we retained the standard deviations (SD) across all annual animal GPS location data for a given trajectory. Density was estimated at the scale of the population, but varied between years and therefore was variable for each roe deer movement trajectory. We used the Analysis of Deviance (ANODEV) method to quantify the amount each variable accounted for in migration probability (Grosbois et al. 2008). The ANODEV compares the deviance of three models including the basic intercept model, an intermediate model and a more complex model. The $R^{2}$ of the ANODEV measures the proportion of variation in migration probability that is accounted for by each additional variable. Our intermediate model included only population density of roe deer $/ \mathrm{km}^{2}$ for each of the five study areas (see Appendix S1: Table S1 for details). The complex model included the variables describing temporal variation of forage resources or their spatial variation measured as SD across all annual locations of individuals. We transformed nonlinear covariates upon visual inspection and screened all covariates for collinearity using the Pearson's correlation coefficient threshold of $|r|>0.6$ (Hosmer and Lemeshow 2000). We chose our top model based on the Akaike Information Criterion for small sample sizes $\left(\mathrm{AIC}_{\mathrm{c}}\right.$, Burnham and Anderson 2002).

\section{Identification and definition of ecological niche variables}

We used a suite of environmental variables to describe realized ecological dimensions at used roe deer locations to assess the patterns of migration in ecological niche space (Fig. 2, Objective 1b; Ecological space) and assessed the determinants of migration (Fig. 2, Objective 2; Determinants; see Appendix S2: Table S1 for details). For each analyses we chose ecological niche variables based on existing knowledge of ungulate and roe deer migration and behavior (Mysterud 1999, Cagnacci et al. 
2011). Habitat variables describing seasonal ungulate habitat use, commonly include topographic features, forage availability, landcover types, and predation or human-caused mortality risk (Fryxell and Sinclair 1988, Albon and Langvatn 1992, Hebblewhite and Merrill 2009, Singh et al. 2012).

To quantify seasonal niche overlap and estimate the ecological migration distance (Fig. 2, Objective 1b; Ecological space) we used growing season vegetation productivity, topographic and landcover variables describing patterns of migration in ecological space. Specifically, for large herbivores forage availability is often described using remotely sensed vegetation indices such as the Normalized Difference Vegetation Index (NDVI) and large herbivore seasonal movements has been shown to correlate with NDVI (Hebblewhite et al. 2008, Bischof et al. 2012, Morellet et al. 2013). We used MODIS satellite NDVI raster layers with a temporal resolution of 16 days and a spatial resolution of $250 \mathrm{~m}$ (Huete et al. 2002). NDVI data were smoothed using methods described by Maselli (2004). We calculated the SD and average NDVI for each pixel during each growing season (nine 16-d NDVI composite rasters between May and September). We chose to characterize the realized niche dimensions for all roe deer using time-invariant habitat variables, but accounted for between-year variation by matching growing season values with roe deer location data for each individual migration year between 2005 and 2013. Further, topography has been shown to affect seasonal movements of large herbivores, including aspect (Mysterud et al. 2011), slope (Cagnacci et al. 2011) and elevation (Albon and Langvatn 1992). We used digital elevation models (DEMs) with a $30-\mathrm{m}$ resolution for latitudes less than $60^{\circ} \mathrm{N}$ (Jarvis et al. 2008) and a $90-\mathrm{m}$ resolution for latitudes more than $60^{\circ} \mathrm{N}$ (Hirano et al. 2003) from which we derived elevation, slope, ruggedness and aspect. We characterized land use with the $100 \mathrm{~m}$ resolution EEA-Corine Landcover Classification (CLC) 2006 and grouped landcover types into eight classes (Appendix S2: Table S1).

Upon classifying migratory behavior we explored the determinants of the different migration strategies (Fig. 2, Objective 2; Determinants). To compare seasonal realized niches of individual roe deer with different migration strategies we used several variables in addition to those described above that have been hypothesized to influence migratory behavior (Fig. 2, Objective 2a; Seasonal discriminators). Climate has been shown to affect seasonal ungulate movements (Nicholson et al. 1997, Ball et al. 2001, Cagnacci et al. 2011). Especially winter conditions may limit ungulate habitat use by restricting movements in deep snow and forage accessibility. We used a winter severity index based on MOD10A2 16-day composite maximum snow extent data at a resolution of $250 \mathrm{~m}$ (Hall et al. 2000, see Appendix S2: Table S1 for details). Because temperature is an important predictor for contrasting summer and winter ranges at different altitudes, we also included the average annual temperature (Hijmans et al.
2005). We contrasted winter and summer niches also in terms of periodic vegetation variability using contingency, constancy, and overall predictability of NDVI (Colwell 1974). Next, escaping risk due to predation and human-caused mortality is another hypothesis to explain migration (Fryxell and Sinclair 1988). To be as inclusive as possible in characterizing seasonal roe deer niches we also we used proxies to characterize overall risk. We described human activity using the $1000 \mathrm{~m}$ resolution nightlights index (Small et al. 2005, Morellet et al. 2013) and general cover using the $250 \mathrm{~m}$ resolution percentage canopy closure (Hansen et al. 2013), because previous studies showed that roe deer sought dense cover potentially to reduce risk (Mysterud and Ostbye 1995, Lone et al. 2014).

Last, to test for the hypothesized relationships between migration probability and the broad-scale parameters of spatiotemporal forage variability $\left(H_{3.1}\right)$ and density ( $H_{3.2}$; Fig. 2, Objective 2b; Broad-scale determinants), we used several synthetic broad-scale variables listed in Appendix S2: Table S1 sampled across annual roe deer ranges. These variables included contingency, constancy and predictability of NDVI (Colwell 1974), which measure seasonality, between-year variability and overall predictability of forage resources, respectively. We produced spatial rasters of contingency and constancy following methods described by English et al. (2012) based on Colwell (1974) using the same smoothed NDVI data as above with a $250 \mathrm{~m}$ spatial and 16-day temporal resolution between 2001 and 2012. In the case of complete constancy, NDVI would remain the same in all seasons and all years, while in the case of complete contingency NDVI would show seasonal patterns that are the same for all years (Colwell 1974). We also calculated the SD of contingency, constancy and predictability across all individual animal location data as a measure of spatial variation of forage resources. Last, roe deer densities were estimated with different methods across our five study areas including fecal pellet distance sampling, infrared camera distance sampling and hunting bag estimates (see Appendix S1: Table S1 for more information). Prior to each analysis, we screened variables for outliers and considered log-transformations for continuous variables when relationships between variables appeared to be non-linear.

\section{Results}

\section{Objective 1: Describing patterns of migration plasticity}

Objective 1a: Describing migration plasticity in geographic space. - In general, when comparing the classification by the two geographic-based methods we found substantial differences in classifications. To facilitate the comparison of classifications between the NSD and the spatial clustering method, we combined individuals identified as migrants, mixed migrants and dispersers vs. residents identified with the NSD, because the spatial clustering 
TABLE 1. Proportions of 71 annual roe deer (Capreolus capreolus) trajectories classified into seasonal movement behavioral categories across five study areas in Europe based on the geographic distance, ecological distance, spatial clustering, and an integrated approach using a $k$-means clustering algorithm.

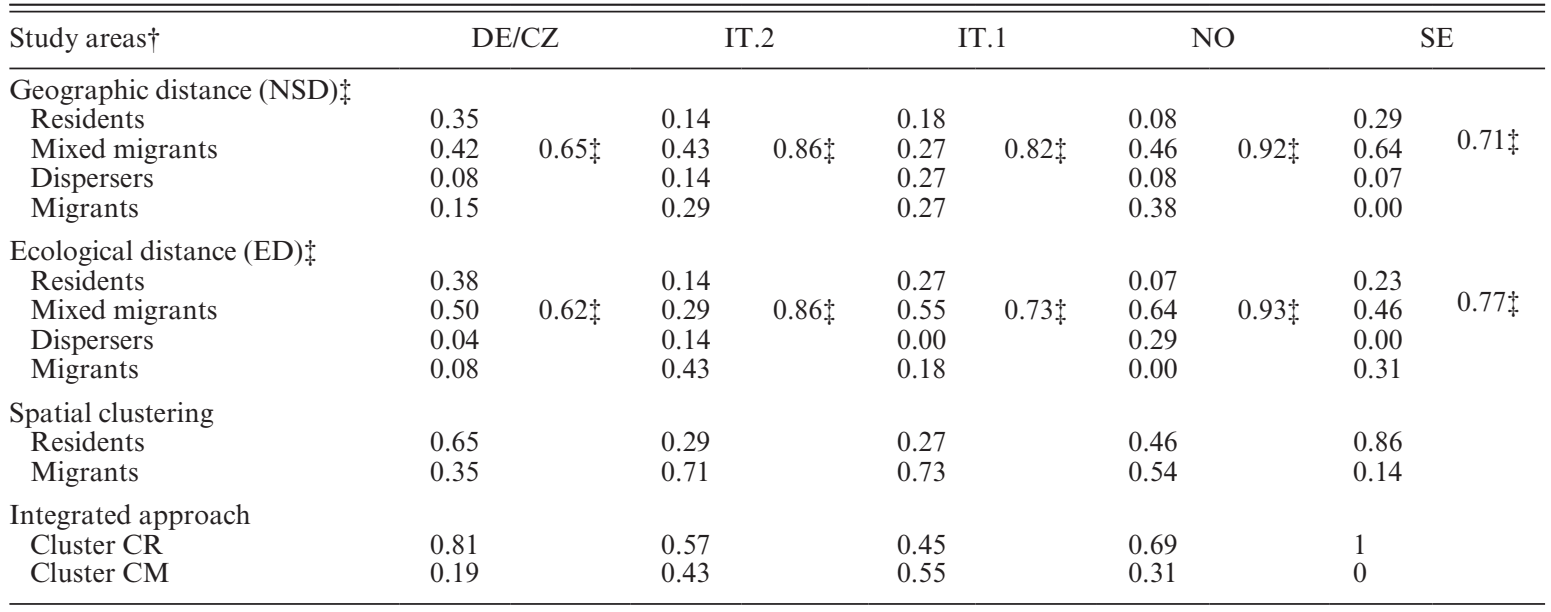

Notes: The integrated approach identified two clusters, where one cluster (CR) was characterized by roe deer showing predominantly resident characteristics while the second cluster $(\mathrm{CM})$ was characterized by animals showing predominantly characteristics of migrant animals. Roe deer GPS data were collected between 2005 and 2013.

$\dagger \mathrm{DE} / \mathrm{CZ}$, Germany/Czech Republic $(n=26)$; IT.2, Italy-Bondone $(n=11)$; SE, Sweden $(n=14)$; NO, Norway $(n=13)$; IT.1, Italy-Rendena $(n=7)$.

\$All movement tactics undergoing seasonal shifts (migration, mixed migration, dispersal) were pooled to be compared to the spatial clustering method that does not differentiate between different non-resident tactics. See Results, Objective 1a for details.

method does not differentiate between movement tactics with more than one annual range. The lowest agreement between the two geographic based methods was found in Sweden (SE; Table 1). Here, the NSD classified $71 \%$ of the roe deer as migrants (i.e., when combining migrants, mixed migrants and dispersers to make both methods comparable), while the spatial clustering identified only $14 \%$ as migrants, although NSD mainly found mixed migration and no animal was classified as a clear migrant. Highest agreement was found in the Italian Bondone population (IT.2), where the spatial clustering method identified $73 \%$ as migrants and the NSD $82 \%$. Despite these classification discrepancies, the two geographic measures used, yielded similar results in terms of distances between winter and summer locations (Table 2). For example, migration distance measured by $\delta$ from the NSD and the distance between seasonal geographic clusters from the spatial clustering method were highly correlated with an $r=0.98$. The high proportion of dispersers identified (up to $27 \%$, Table 1) by the NSD method was surprising, because we excluded age classes that are known to disperse a priori (Wahlström and Liberg 1995).

Objective 1b: Describing migration plasticity in ecological space. - The ED method suggested that roe deer in all five study areas show some kind of migration in ecological niche space. When combining all ED categories that indicate a shift between the summer and the winter niche (e.g., migration, mixed migration, and dispersal), we found that $73 \%$ in the Italian Rendena (IT.1) population, $86 \%$ in the Italian Bondone (IT.2) population, 93\% in Norway (NO), $62 \%$ in Bavaria (DE/CZ), and $77 \%$ in
Sweden travel across an ED to some degree. Notably, the mixed migration category was the dominant category for all five study areas, suggesting quite a bit of classification uncertainty. Average niche overlaps between winter and the following summer ranged from a Schoener's $D$ of 0.39 in the Italian Rendena (IT.1) population, 0.42 in

TABLE 2. Averages and standard deviations (SD; in parenthesis) for different roe deer (Capreolus capreolus) migration measures identified by $k$-means cluster analysis with $k=2$ (CR, resident cluster; $\mathrm{CM}$, migrant cluster).

\begin{tabular}{|c|c|c|}
\hline Parameter & CR & $\mathrm{CM}$ \\
\hline \multicolumn{3}{|l|}{ Ecological distance } \\
\hline $\mathrm{ED}_{\text {wi-su }}$ & $1.72(0.980)$ & $4.48(1.593)$ \\
\hline SD & $0.68(0.349)$ & $1.91(0.806)$ \\
\hline Asymptote ED $\dagger$ & $0.002(0.001)$ & $0.01(0.002)$ \\
\hline \multicolumn{3}{|l|}{ Seasonal niche overlap } \\
\hline Schoener's $D$ & $0.61(0.200)$ & $0.22(0.175)$ \\
\hline \multicolumn{3}{|l|}{ Seasonal location overlap } \\
\hline Migration $(\%)$ & 25 & 100 \\
\hline Cluster distance $(\mathrm{km})$ & $1.47(2.822)$ & $10.68(8.202)$ \\
\hline \multicolumn{3}{|l|}{ Cartesian distance } \\
\hline Asymptote NSD $\$(\mathrm{~km})$ & $1.54(4.165)$ & $10.59(8.247)$ \\
\hline \multicolumn{3}{|l|}{$k$-means clustering } \\
\hline Silhouette width & $0.55(0.190)$ & $0.48(0.152)$ \\
\hline
\end{tabular}

Notes: Migration measures include the difference in ecological distance $(E D)$ between winter vs. summer $\left(\mathrm{ED}_{\text {wil-su }}\right)$, the annual SD of ED, the asymptote from ED models, the Schoener's niche overlap $(D)$ between winter and the following summer, the percentage of individuals classified as migrants based on the seasonal clustering method, the associated distance between cluster centers, and the asymptote of the NSD. Finally, the silhouette widths are provided for each cluster.

$\dagger$ Square-root transformed and multiplied by 100000 .

$\$$ Square-root transformed. 
the Italian Bondone (IT.2) population, 0.54 in Norway (NO), 0.50 in Bavaria (DE/CZ), to 0.62 in Sweden (SE; Fig. 4).

Objective 1c: Comparison and integration: toward a combined approach for the classification of migratory behavior.-We found a significant negative relationship between niche overlap $(D)$ and geographic migration distance in $\mathrm{km}$ from NSD (log-transformed, $r=-0.63$, $F=46.15$, df $=1,69, P<0.001$; Fig. 4). Similarly, also, $\delta$ from ED increased with $\delta$ from NSD (both logtransformed, $r=0.64, F=47.76$, df $=1,69, P<0.001)$. The relationship between geographic distance and niche overlap was significant and suggested that, the further animals migrated in geographic space, the lower their seasonal niche overlap was for most study populations $\left(r_{\text {Rendena, IT }}^{2}=0.798, r_{\text {Nina, } \mathrm{NOR}}^{2}=0.861, r_{\text {Bondone } \text { IT }}^{2}=0.784\right.$, $r_{\text {Bavaria, GER }}^{2}=0.436$; all $P$ values $\left.<0.001\right)$. We found no significant relationship $\left(P\right.$ value $\left.=0.635, r^{2}=0.010\right)$ in Koberg, Sweden (Fig. 4 and Appendix S3: Fig. S1). Overall, these results confirm our prediction under the ecological migration distance hypothesis $\left(H_{1}\right)$ that migration in roe deer not only entails shifts in geographic space, but can also be measured in ecological niche space $\left(P_{1}\right)$. The strength of this relationship, however, seems to be dependent on the composition and heterogeneity of the landscape an individual inhabits (Appendix S3: Fig. S1).

When comparing the classification of migratory behavior using geographic and ecological approaches, we

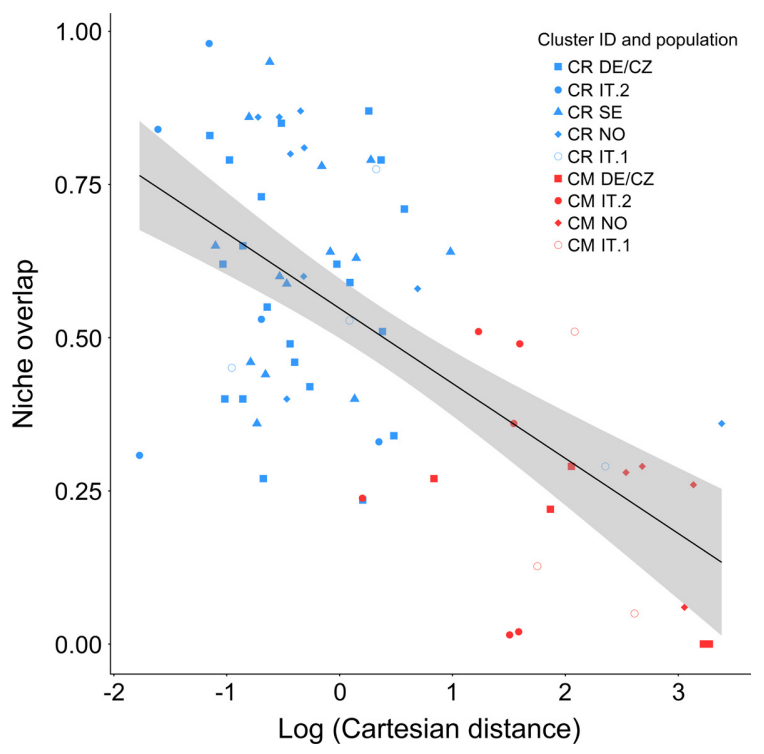

FIG. 4. The log-transformed Cartesian migration distance (with 95\% CI; measured in $\mathrm{km}$ ) against Schoener's niche overlap $(D)$ by the classification using the integrated $k$-means cluster analysis into resident (cluster CR; $n=53$ ) and migrant (cluster $\mathrm{CM} ; n=18$ ) annual roe deer (Capreolus capreolus) trajectories and by study populations used including Germany/Czech Republic (DE/CZ, $n=26)$, Italy-Bondone (IT.2, $n=11)$, Sweden (SE, $n=14$ ), Norway (NO, $n=13$ ) and Italy-Rendena (IT.1, $n=7)$. found both similarities and differences (Table 2). An average Kappa statistic of 0.52 across all populations suggests only fair agreement between the NSD and ED measures. Overall we found the Kappa-based agreement to range between poor (0.35) and good (0.65; Monserud and Leemans 1992). For example, for the German/Czech roe deer population (DE/CZ) using the NSD method 15\% of all DE/CZ roe deer were classified as migrants, $42 \%$ as mixed migrants, $35 \%$ as residents, and $8 \%$ as dispersers. Using ED $8 \%$ were clear migrants, 50\% were mixed migrants, $38 \%$ were residents, and only $4 \%$ were classified as dispersers (Table 2). The Kappa statistic for this population was 0.46 , suggesting fair agreement between the two classification systems. We found the following agreement based on the Kappa statistic for the other study populations: the Italian-Bondone population $=0.52$, the Italian Rendena population $=0.59$, the Swedish population $=0.35$, and the Norwegian population $=0.65$.

The optimal number of clusters determined for the measures of the geographic space was 12 with the maximum discrimination ability of a silhouette width of 0.86 (ranges between 0 and 1; Fig. 5). This indicates that there was a very clear structure to the clusters, with most observations seeming to belong to the cluster that they were assigned to (e.g., Rousseeuw 1987). Overall, the 12 clusters identified seemed to correspond to differences in individual movement strategies within the five study areas, and were largely descriptive groupings along the continuum of migratory "tendency" from residency to clear migration. Using the ecological measures only, an average silhouette of $\bar{S}(k)=0.45$ was achieved with three clusters, which loosely represented migrant, resident, and an intermediate strategy. A $\bar{S}(k)=0.45$ indicates that there was structure identified in the data, but not as strong as the geographic approach. A silhouette of 0.51 (indicating that a reasonable structure has been found) was achieved with only two clusters (separating roe deer with more migratory vs. resident tactics) for the integrative approach, which combined all measures of geographic and ecological space (Fig. 5). Although geographic measures found a stronger structure in 12 groups, the integrative combination of ecological and geographic measures provided a more parsimonious explanation (here, in the sense of fewest categories) of variation in migratory behavior of roe deer. But, the most appropriate method to classify migrants, residents, and tactics in between these endpoints of the migration continuum may be case dependent. The high variation within and between the approaches based on geographic and ecological space, suggested that in our case, migration may be best described with a combination of measures. In this way, we were able to combine the main definitions for migration, the spatial separation of seasonal ranges as well as the ecological shift in habitat components. Consequently, the combination of all classification approaches seemed appropriate to address our second major question on the determinants explaining differences in seasonal movements (Fig. 1; Objective 2, Determinants). 

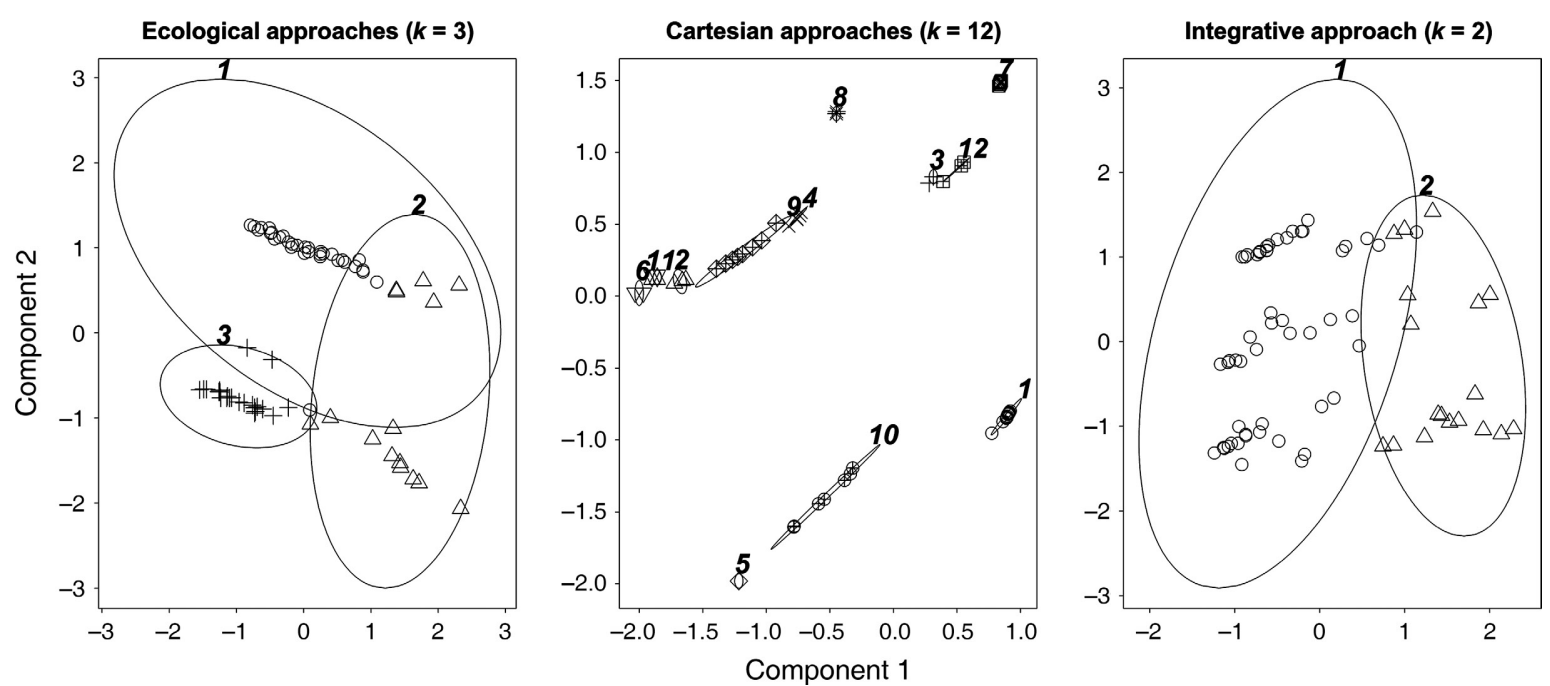

FIG. 5. Clusters identified based on the highest average silhouette width for ecological distance approaches only $(\bar{S}(k)=0.45$; left panel), Geographic/Cartesian approaches only $(\bar{S}(k)=0.86$; center panel) and the integrative classification with the ecological and Cartesian approaches combined $(\bar{S}(k)=0.51$; right panel).

Based on the integrative classification, one of our two clusters contained more animals showing characteristics of the resident tactic $(75 \%$ were residents according to the spatial clustering method, Table 2, herein called resident cluster, $\mathrm{C}_{\mathrm{R}}, n=53$ ). The second cluster included migration years during which roe deer showed migration characteristics (e.g., 100\% were migrants according to the spatial clustering method; Table 2, herein called migrant cluster, $\left.\mathrm{C}_{\mathrm{M}}, n=18\right)$. The $\bar{S}(k)$ of $\mathrm{C}_{\mathrm{R}}$ was 0.55 , while the $\bar{S}(k)$ of $\mathrm{C}_{\mathrm{M}}$ was 0.48 . Overall, individuals classified in $C_{R}$ had smaller average Cartesian and EDs and seasonal location and niche overlap values (Table 2). More specifically, we found average niche overlaps of 0.58 for animals falling in the resident cluster $\left(C_{R}\right)$ and 0.16 for animals falling in the migrant cluster $\left(\mathrm{C}_{\mathrm{M}}\right)$ in Bavaria, $\mathrm{DE} / \mathrm{CZ}, 0.60$ for residents and 0.27 for migrants in Bondone, IT, 0.62 for residents only in Koberg, SE, 0.68 for residents and 0.22 for migrants in Norway and 0.51 for residents and 0.23 for migrants in Rendena, IT. Both clusters showed differences in their average geographic and ecological migration indices, where cluster $C_{R}$ indicated smaller average distances and higher overlap values (Table 1, Fig. 3 and Appendix S1: Table S1).

\section{Objective 2: Assessing determinants of migration plasticity}

Objective 2a: Determinants underlying seasonal roe deer niches.-The permutation test of the DA indicated that the four groups (i.e., the combinations of two seasons and two-class migratory status) were significantly different $(P<0.001)$. While both realized seasonal ecological niches of residents $\left(C_{R}\right.$, the resident cluster $)$ indicated a high degree of similarity in environmental variables, the biplot (Fig. 6) showed a distinct separation of the realized seasonal ecological niches for migrants $\left(\mathrm{C}_{\mathrm{M}}\right.$, the migrant cluster). This later observation offers additional confirmation for our prediction under the ecological migration distance hypothesis $\left(H_{1}\right)$, that seasonal niche overlap is lower for migrants than for residents $\left(P_{1}\right)$. As expected, niches of resident and migrants differed most in summer $\left(P_{2.3}\right)$. Interestingly, however, while we expected niches of residents and migrants to differ especially for the migratory summer season when the total range of the species expands, winter niches of residents and migrants also differed slightly (Fig. 6). The first discriminant component (DS1), which contributed $54 \%$ to the explained variance, mainly separated the seasonal niches of the migrant cluster $\left(C_{M}\right)$ from both seasonal niches of the resident cluster $\left(C_{R}\right)$. Both seasonal niches of migrants were associated with this first component. In contrast, the second discriminant component (DS2), which contributed $46 \%$ to the explained variance, mainly separated the summer niches of migrants from the winter niches of both residents and migrants (Fig. 6, Table 3). Consequently, environmental variables that were negatively correlated with DS 1 were associated with $C_{M}$ and environmental variables positively correlated with DS 1 were associated with $C_{R}$ (the resident cluster). In contrast, environmental variables that were negatively correlated with DS 2 were associated with summer niches and environmental variables positively correlated with DS 2 were associated with winter niches.

Environmental variables discriminating both realized seasonal ecological niches of migrants from residents indicated that resident roe deer were characterized by lower SD in NDVI (DS1 $=-0.80$ ), lower elevations $(\mathrm{DS} 1=-0.55)$, less steep slopes $(\mathrm{DS} 1=-0.48)$, and less rugged terrain $(\mathrm{DS} 1=-0.40)$. Overall, these results confirm our predictions under the forage maturation hypothesis $\left(H_{2.1}\right)$ that $\left(P_{2.1}\right)$ migrant summer niches would be mainly associated with increased forage productivity. Next, variables explaining differences between 


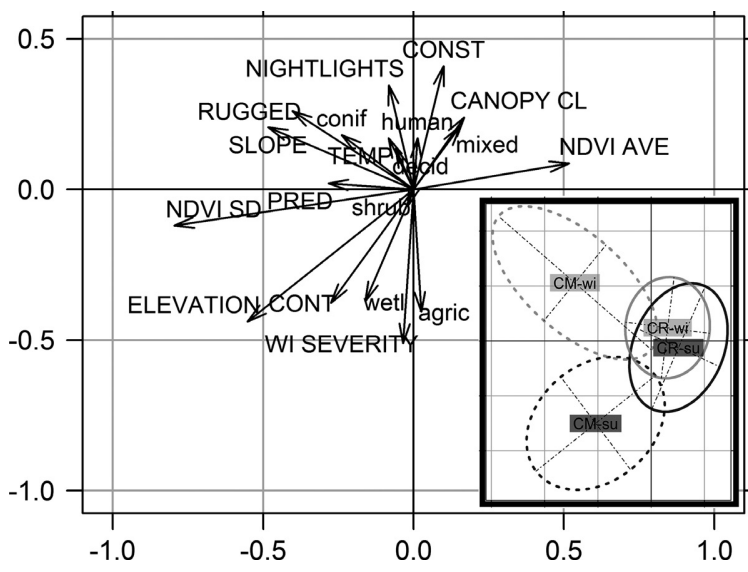

FIG. 6. Canonical plot of the first two canonical axes of the discriminant analysis on environmental variables averaged for GPS roe deer (Capreolus capreolus) location data classified into two movement tactics (migrants, $n=18$; residents, $n=53$ ) and two seasons (summer and winter). The larger plot shows the canonical scores (i.e., coefficients) of the linear discriminant function on the first two axes of the analysis. All categorical landcover types are lowercase, all other variables uppercase and abbreviations are explained in Table 3. The smaller inset plot shows the discrimination between the winter migrant cluster (CM-wi), summer migrant cluster (CM-su), winter resident cluster (CR-wi) and the summer resident cluster (CR-su), where the centers represent the group means (the between variances) and the ellipses are the within group variances. The proximity between the different season/movement type groups is linked to their similarity in niche composition. Roe deer GPS location data were collected between 2005 and 2013 in five European study areas.

winter and summer niches, especially of migratory roe deer, included winter severity (DS2 $=-0.51$ ), elevation $(\mathrm{DS} 2=-0.44)$, percent agriculture in seasonal ranges (DS2 $=-0.41$ ), and constancy of NDVI between years $(\mathrm{DS} 2=0.41)$. Especially winter severity suggests that migrants cannot remain on their summer ranges due to the limiting winter conditions there, possibly restricting movements and forage accessibility, confirming our prediction $\left(P_{2.2}\right)$ under winter conditions hypothesis $\left(H_{2.2}\right)$.

In general, variables that were mainly associated with summer niches of migrants (i.e., negative on DS1 and DS2) were elevation (DS1 $=-0.55$, DS2 $=-0.44)$, seasonality (contingency; DS1 $=-0.27, \mathrm{DS} 2=-0.38$ ) and the proportion of conifer forest within summer ranges (DS1 $=-0.24$, DS2 $=-0.37$ ). Winter niches of migrants (i.e., negative on DS1 and positive on DS2) were mainly associated with slope (DS1 $=-0.48$, DS2 $=0.21)$ and ruggedness (DS1 $=-0.40, \mathrm{DS} 2=0.26$, Fig. 6 ). In contrast, winter niches of residents (i.e., positive on DS1 and DS2) showed highest association with average NDVI within their winter ranges $(\mathrm{DS} 1=0.52, \mathrm{DS} 2=0.09)$ and higher canopy closures $(\mathrm{DS} 1=0.17, \mathrm{DS} 2=0.24)$. Summer niches of residents (i.e., positive on DS1 and negative on DS2) were mostly associated with agriculture (DS1 $=0.03$, DS2 $=-0.41 ;$ Fig. 6 , Table 3).

Objective 2b: Broad-scale determinants of migratory probability.-Among the variables contingency (seasonality), constancy (between-year variability), and overall temporal predictability (sum of contingency and constancy), characterizing temporal variation, contingency was the only variable that was marginally significant and accounted for $31 \%$ of the variation in migration probability. This relationship offers some evidence for the first part of our predicted relationship between migration probability and seasonality of forage resources under the spatiotemporal resource hypothesis $\left(H_{3.1}\right.$; Table 4$)$, that the probability of migration in roe deer would be higher in more seasonal landscapes $\left(P_{3.1}\right)$. But, in contrast to just temporal variability in forage, the probability of migration increased for variables incorporating temporal and spatial variation, supporting the second part of our prediction derived under the spatiotemporal resource variability hypothesis $\left(H_{3.1}\right)$, that increased spatial heterogeneity of seasonal forage resources at the annual scale (broad-scale) would increase the probability of migration $\left(P_{3.1} ;\right.$ Fig. 7). All three variables characterizing spatial variability of forage variation (SD of contingency, constancy, and predictability) were statistically significant (Table 4) and accounted for a good proportion of the variance in migration probability $\left(R_{\mathrm{ANODEV}}^{2}=0.55\right.$ $0.64)$. Finally, although our sample size was limited, we found evidence for the competition avoidance hypothesis $\left(H_{3.2}\right)$, predicting that the spatiotemporal variability in forage availability may be modulated by density-dependent competition with an overall higher probability of migration with increasing densities $\left(P_{3.2}\right.$; Table 4 , Fig. 7). The model with the lowest $\mathrm{AIC}_{\mathrm{c}}$ described migration probability as a function of increasing density and increased spatial variability in seasonality (contingency; Fig. 7). Interactions between density and variables characterizing spatiotemporal variation were not statistically significant and neither were random effects to account for within study areas variability and differences in sample sizes.

\section{Discussion}

We applied a conceptually novel ED-based approach, including concepts of realized niche theory, to classify migration using the example of a large herbivore with high ecological plasticity across a range of study sites. We also assessed the determinants of contrasting seasonal movement strategies. Thereby, we addressed the link between a variety of individual migratory movements and the realized ecological niches in the different environments in which they occur. As a prerequisite to our integrated classification approach, we compared distance and overlap measures in ecological niche space and geographic space (Fig. 4; Appendix S3: Fig. S1) and our results indicated that migratory roe deer move to different environmental niches, and thereby travel an ED. In contrast, residents largely remained within the same niches year around, but also showed small niche shifts (e.g., niche overlap was never $100 \%$ ). We were then able to use the migration measures estimated in ecological space and combine them with geographic classification measures to achieve an integrative classification of migratory behavior 
TABLE 3. Means of variables and results of the linear discriminant analysis using averaged environmental data by season (winter [wi] and summer [su]) and individual roe deer (Capreolus capreolus) of each cluster separating migrant clusters (CM) and resident clusters (CR) as input matrix.

\begin{tabular}{|c|c|c|c|c|c|c|}
\hline \multirow[b]{2}{*}{ Covariates } & \multicolumn{4}{|c|}{ Covariate means by group } & \multicolumn{2}{|c|}{ Canonical scores } \\
\hline & CR-su & CM-su & CR-wi & CM-wi & $\mathrm{CS} 1$ & $\mathrm{CS} 2$ \\
\hline CANOPY CL (Canopy closure) & 47.07 & 38.25 & 51.94 & 46.67 & 0.17 & 0.24 \\
\hline NIGHTLIGHTS (Nightlights) & 11.15 & 5.08 & 12.74 & 20.16 & -0.08 & 0.35 \\
\hline CONST (Constancy) & 0.25 & 0.21 & 0.28 & 0.28 & 0.10 & 0.41 \\
\hline CONT (Contingency) & 0.32 & 0.39 & 0.30 & 0.33 & -0.27 & -0.38 \\
\hline ELEVATION (Elevation [m]) & 575.62 & $1,232.38$ & 566.54 & 825.03 & -0.55 & -0.44 \\
\hline SLOPE (Slope [degrees]) & 9.22 & 12.64 & 9.71 & 19.39 & -0.48 & 0.21 \\
\hline PRED (Predictability) & 0.58 & 0.60 & 0.58 & 0.61 & -0.28 & 0.02 \\
\hline WI SEVERITY (Winter severity) & 0.59 & 0.73 & 0.58 & 0.50 & -0.03 & -0.51 \\
\hline RUGGED (Ruggedness) & 10.88 & 12.83 & 11.25 & 22.78 & -0.40 & 0.26 \\
\hline TEMP (Annual mean temperature) & 6.50 & 5.69 & 6.06 & 6.88 & -0.08 & 0.17 \\
\hline NDVI SD (SD NDVI) & 0.11 & 0.18 & 0.11 & 0.18 & -0.80 & -0.12 \\
\hline NDVI AVE (mean NDVI) & 0.76 & 0.71 & 0.76 & 0.71 & 0.52 & 0.09 \\
\hline human $(\%$ Human lc) & 1.49 & 0.00 & 3.64 & 3.49 & 0.01 & 0.17 \\
\hline agric (\% Agricultue lc) & 20.51 & 29.09 & 8.80 & 5.28 & 0.03 & -0.41 \\
\hline decid (\% Deciduous lc) & 11.94 & 4.97 & 5.62 & 16.34 & -0.06 & 0.14 \\
\hline wetl $(\%$ Wetland lc) & 0.84 & 4.38 & 0.03 & 0.17 & -0.16 & -0.37 \\
\hline conif $(\%$ Conifer lc) & 2.49 & 2.51 & 1.48 & 11.56 & -0.24 & -0.37 \\
\hline mixed (\% Mixed lc) & 37.06 & 24.97 & 48.12 & 37.04 & 0.15 & 0.21 \\
\hline shrub (\% Shrubs lc) & 25.67 & 34.07 & 32.30 & 26.12 & -0.02 & -0.06 \\
\hline DS1 & 0.51 & -1.04 & 0.31 & -1.43 & & \\
\hline DS2 & -0.12 & -1.50 & 0.24 & 1.06 & & \\
\hline
\end{tabular}

Notes: Canonical scores (CS) represent the standardized canonical discriminant function coefficients of all variables along the two dimensions identified. The class scores (DS) represent the centroid coefficients of each group (group centroids) in ordination space defined by the two dimensions. NDVI, Normalized Difference Vegetation Index.

(Fig. 2, Objective 1; Patterns). Next, the results of our second objective (Fig. 2, Objective 2; Determinants) allowed us to measure many of the factors of migration earlier reported in other large herbivore species simultaneously across five roe deer study areas that broadly supported the FMH as the driver of migration in roe deer. We found evidence for the importance of spatiotemporal variation in forage resources hypotheses (resource seasonality and spatial variability) and our results further suggest that density modulates roe deer migration. Especially the effects of density on migration probability require further investigation with larger sample sizes, and a finer spatial resolution of density. Our work is among the broadest tests of the determinants of roe deer migration yet conducted, and our approach allowed us to demonstrate that individual migration propensity appears to be affected by terrain, climate, and forage variability and predictability.

Objective 1: Describing patterns of migration plasticity: toward an integrative classification of migratory behavior and ecological implications

Classification of migration is a key step before being able to test hypotheses about determinants of migration.

TABLE 4. Candidate logistic regression models describing the probability of migration for 71 annual roe deer (Capreolus capreolus) trajectories in five European study areas.

\begin{tabular}{lccccccc}
\hline \hline \multicolumn{1}{c}{ Model } & $\beta_{\text {density }}$ & $\beta_{\mathrm{x}}$ & $P_{\text {density }}$ & $P_{\mathrm{x}}$ & $\mathrm{AIC}_{\mathrm{c}}$ & $\Delta \mathrm{AIC}_{\mathrm{c}}$ to $M_{\mathrm{i}}$ & $R_{\text {ANODEV }}^{2}$ \\
\hline Density + contingency SD log $\dagger$ & 0.313 & 1.197 & 0.033 & 0.002 & 57.72 & 0.00 & 0.64 \\
Density + predictability SD log $\dagger$ & 0.453 & 1.115 & 0.002 & 0.007 & 61.68 & 3.96 & 0.56 \\
Density + constancy SD log $\dagger$ & 0.317 & 0.989 & 0.022 & 0.009 & 62.19 & 4.47 & 0.55 \\
Density + contingency & 0.276 & 8.016 & 0.035 & 0.081 & 67.77 & 10.05 & 0.31 \\
Density + constancy & 0.320 & -4.968 & 0.125 & 0.274 & 69.75 & 12.03 & 0.15 \\
Density + predictability & 0.299 & 7.848 & 0.021 & 0.277 & 69.83 & 12.11 & 0.14 \\
Density & 0.333 & - & 0.008 & - & 71.03 & 13.30 & 0.00 \\
Intercept model & - & - & - & - & 78.40 & 20.67 & - \\
\hline
\end{tabular}

Notes: Predictor variables included population density, the overall predictability of the Normalized Difference Vegetation Index (NDVI; a proxy for vegetation productivity), between-year variability of NDVI (constancy) and seasonality of NDVI (contingency). The SD of these three measures gives an index of spatiotemporal variation of NDVI measured within annual ranges of roe deer. The $R_{\mathrm{ANODEV}}^{2}$ describes the proportion of variation in migration probability that is accounted for by any given variable describing temporal or their spatiotemporal variation. We provide the model coefficients $(\beta)$ for density and the additional parameters included in each model $(x)$, their $P$ values $(P)$, Akaike Information Criterion for small sample sizes $\left(\mathrm{AIC}_{\mathrm{c}}\right)$, the difference in $\mathrm{AIC}_{\mathrm{c}}$ to the null model $\left(\triangle \mathrm{AIC}\right.$ c to $\left.M_{\mathrm{j}}\right)$ and the $R_{\mathrm{ANODEV}}^{2}$. GPS movement data were collected between 2005 and 2013. The dashes indicate that no estimates are available (i.e., NA).

$\dagger$ Log transformed. 

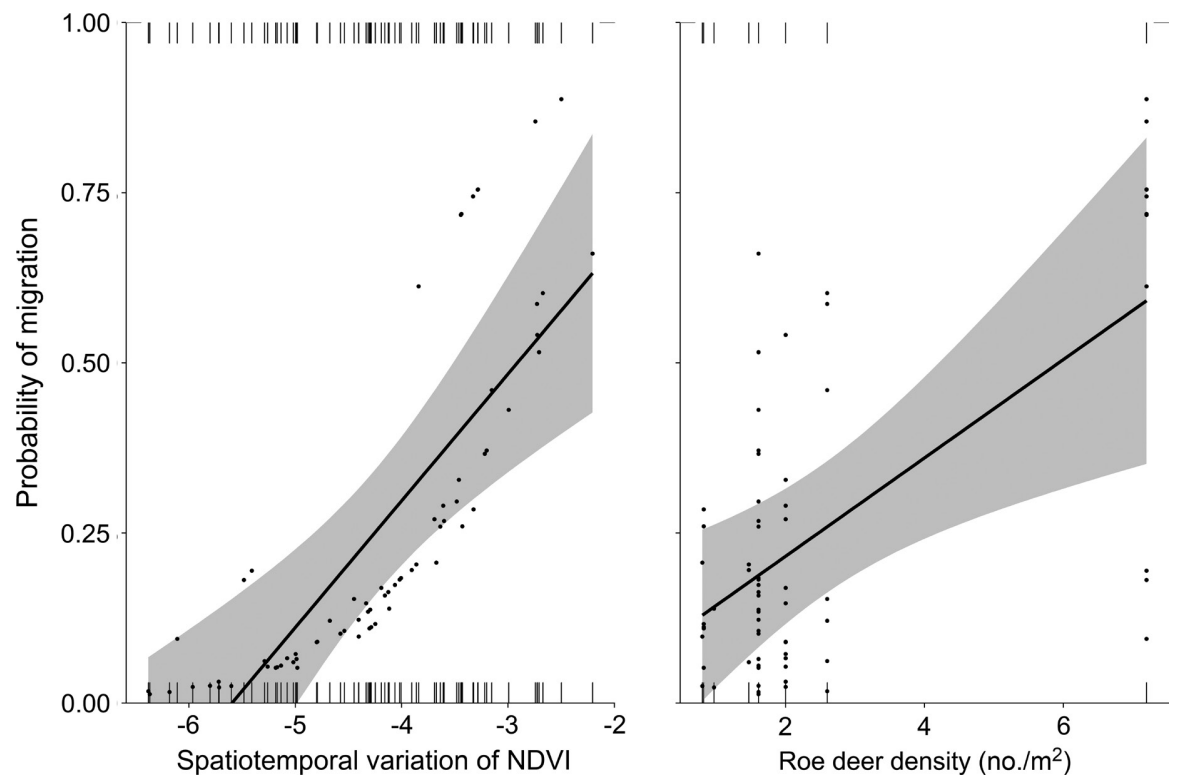

FIG. 7. Model predictions from our top logistic regression model explaining migration probability in roe deer (Caproelus capreolus) as a function of spatial variation of seasonal vegetation resources (SD of contingency measured within annual roe deer ranges; left panel) and density (right panel) across five European study populations and. Contingency was estimated with time series data of the Normalized Difference Vegetation Index (NDVI) collected between 2000 and 2014. Roe deer were monitored between 2001 and 2012.

However, migration classification has been a muchdiscussed problem in ecology (Cagnacci et al. 2016). Consistent with a growing number of recent studies, we also found substantial variation in the classification of roe deer movement strategies using common geographic measures. For example, Cagnacci et al. (2016) found that consistency between three classification methods based on geographic space was only $50 \%$ and no method clearly outperformed another. Individuals falling toward the endpoints of the migration continuum (clear residency or clear migration; Cagnacci et al. 2011) were usually classified consistently between methods in our and previous studies (Cagnacci et al. 2016). In contrast, individuals displaying equivocal movement strategies across short geographic distances (with multiple trip migrations or overall low range fidelity), commonly observed in partially migratory populations of species with high ecological plasticity, showed substantial disagreement between methods.

The NSD method has recently become the standard for classification of migratory behavior, especially for mammals. When applying the NSD method to simulated data, Bunnefeld et al. (2011) found high agreement between the simulated patterns and the NSD classification results for mixed migration, migration, and dispersal. But, the NSD method misclassified $58 \%$ of all simulated individuals displaying resident behavior and interestingly, misclassifications of residents were commonly identified as dispersers (36\%; Bunnefeld et al. 2011). This confirms that resident strategies may be underestimated in studies using this method without applying additional measures, such as a minimum distance moved criterion (Mysterud et al. 2011, Eggeman et al. 2016), or visual inspection of trajectories (Bischof et al. 2012), which is, however, often done. Indeed, the NSD method also identified a high proportion of dispersers in our data set, which was surprising, because we only used data from adult roe deer and dispersal is commonly restricted to juveniles (Wahlström and Liberg 1995). We find it likely that the "dispersers" identified in our data set were misclassified residents and mixed migrants (e.g., Bunnefeld et al. 2011). Our integrative approach discriminated higher proportions of residents in all study populations compared to the geographic and ecological classification methods alone (Table 1).

Migratory plasticity is one of the main reasons why unambiguous classification is so difficult (Cagnacci et al. 2016). For example, for highly plastic roe deer, the 12 clusters based on geographic measures likely identified each population-specific strategy (Table 1), reflecting the diverse gradient ranging from residency to migration in different habitats (Cagnacci et al. 2011). While this provides an example of over-classification that undermines our attempts to understand the general determinants of migration, the gradient of migration "tendency" ("migratoriness"; Taylor and Taylor 1977) could also provide an opportunity for future research. For example, understanding the factors that affect placement of individual animals along such a residency-to-migration continuum, could yield important insights into mechanisms underlying intermediate stages, costs and benefits of such tactics and how climate and anthropogenic land use changes may affect transition probabilities along the continuum (Cagnacci et al. 2016). Although studying factors 
affecting the migration continuum is certainly intriguing, our integrative classification approach allowed us to categorize individuals with distinct movement tactics and address the specific hypotheses regarding determinates for migration following our classification.

Testing if roe deer travel an ED was only a prerequisite to develop our integrative migration classification approach, however, our results have interesting ecological implications. For example, estimating the EDs individuals travel, may aid in understanding the diversity of, and gradients or tendencies within, migratory systems (Nakazawa et al. 2004). Traveling across EDs has been related to niche switching or niche following and may be a function of the plasticity of a species (Laube et al. 2015) as well as the heterogeneity of the landscapes individuals inhabit (LeResche 1974). To date, studies assessing relationships between seasonal niche overlap are limited to the avian literature. For example, two studies on different species of warblers (Parulidae) suggest that migrants show low niche overlap and therefore switch niches when comparing conditions between breeding and nonbreeding range during different seasons (Gómez et al. 2016), but follow niches when comparing conditions on the breeding and non-breeding range during the same season assessing what birds could have experienced if they stayed (Laube et al. 2015). This emphasizes questions that are fundamentally different from how niche following and ED migration may be defined. Here, we present the first comparison of summer niches of generally plastic roe deer to what they could have experienced if they stayed on winter range year round. We tested this relationship in different study areas (Appendix S3: Fig. S1) and, as suggested by LeResche (1974), the relationship was linked to some degree to the environmental heterogeneity in the different study areas. For example, migrants in the very heterogeneous Italian Alps needed to move shorter distances to achieve larger EDs than roe deer in more homogenous habitats, such as Bavaria, DE/CZ. This suggests that migratory roe deer have broader annual niches, at least for the niche dimensions we measured.

Comparing the summer niches of roe deer to niche conditions they could have experienced if they remained on winter range, our results suggest that migratory roe deer take advantage of improved forage and possibly escape density dependence in summer through niche switching. But, reasons for niche switching may be multifaceted and can only be detected accurately when variables shaping realized seasonal niches are known. Further, related resource selection processes are generally scale-dependent in space and time (Senft et al. 1987, Wiens 1989). For example, it has been suggested that niche dimensions that are being followed are narrower and seasonally variable, while niche dimensions that are being switched are broader and static in time, but variable in space (Laube et al. 2015). While we provide first insights into niche switching by migrants characterizing niches in $n$ dimensions using static variables only, other studies using time-variant variables in only one niche dimension (NDVI) have suggested that migratory as well as resident large herbivores follow gradients of plant green-up as expected in temperate environments (Bischof et al. 2012, Gaudry et al. 2015). Consequently, we would expect niche switching for both migrants as well as residents between seasons when comparing niche dimensions of time-variant variables, such as time-matched NDVI, in seasonal temperate habitats (Mancinelli et al. 2015). For the purpose of classification of migration the use of timevarying covariates would not have been beneficial, but we highlight that the relationship between time-varying covariates and seasonal niches remains to be tested. Besides temporal dimensions, the degree to which niche overlap may also be a function of the spatial resolution of niche variables (Senft et al. 1987). For example, residents may show more fine-scale responses to phenology induced changes in forage digestibility that allow them to compensate for the effects of not migrating, which we would expect for a small concentrateselector(Hebblewhite et al. 2008, Bischof et al. 2012). Overall, while we found no niche following by migrants as a function of a suite of fairly coarse-grained environmental variables, niche following could occur at smaller spatial scales, such as forage patch or forage plant selection.

Last, to test if roe deer travelled across an ED and thereby switched realized ecological niches, we used a presence-only design. We did not compare environmental conditions at used sites with absence- or pseudo-absence data to define niche space availability. Broennimann et al. (2012) showed that when not correcting locations (use) by their environmental prevalence, niche overlap may be underestimated except for niches with very low overlap. In our case, the availability of environmental variables for resident animals was consistent in both seasons and thus, this availability issue will not affect their niche overlap. Further, if niche overlap would be underestimated for migrants, our results would consequently only be stronger when correcting for availability and the niche space was calibrated with occurrence data from both seasonal ranges under the assumption of equal availability. While this assumption may not be applicable to other taxa, for ungulates it appears appropriate, because their decision to migrate reflects resource selection at the landscape scale (Johnson's second order scale; Johnson 1980, Hebblewhite and Merrill 2009). Thus, our results are likely to be robust.

\section{Objective 2: Assessing determinants of migration plasticity: the realized ecological niches of migrants and residents}

The costs and benefits of migration depend on the ecological conditions an individual inhabits and in general animal migration can be driven by forage availability, escape from severe climatic conditions, predation or parasite risk or reproductive constraints (Dingle 1996, Shaw and Couzin 2013). For ungulates in temperate 
environments migration in spring is commonly a function of increased forage availability and decreased competition on allopatric summer ranges, while migration in autumn is typically driven by limiting conditions that make over-wintering on the summer range impossible (Nicholson et al. 1997, Mysterud 1999). Our analysis of the determinants for roe deer migration across five study areas suggested that migration was a function of forage, terrain, and climatic factors. Spatiotemporal variation in NDVI has been correlated with higher forage quality in the growing season (mountainous environments; Hebblewhite et al. 2008). Furthermore, in more diverse landscapes with high topographic and vegetation variability the spatial synchrony of spring is lower and the duration longer prolonging access to highly nutritious early vegetation (Albon and Langvatn 1992, Walker et al. 1993). Plant digestibility and protein content during the growing season are positively correlated with elevation and latitude, which has been linked to benefits of migration (Van Soest 1983). For example, in a study by Nicholson et al. (1997), migratory mule deer, which had increased access to forage in a mountainous region, also had increased reproductive success. Migratory female red deer in Norway had higher body mass and pregnancy rates than residents (Albon and Langvatn 1992). In another study, Norwegian female moose had a higher fecundity and grew to a larger body size than resident moose, possibly due to improved foraging conditions on migrant summer ranges (Rolandsen et al. 2016).

Forage benefits due to migration may be twofold. First, ungulates following phenology gradients can have access to high quality forage while moving (Sawyer and Kauffman 2011). Second, even after arrival on high elevation summer ranges migratory individuals may continue to benefit from prolonged forage quality due to cooler temperatures and delayed snowmelt (Hebblewhite et al. 2008, Bischof et al. 2012). Our results support the latter, but we did not test for the former using timevariant NDVI (see Discussion, Objective 1). Small browsers especially commonly rely on ingesting relatively low amounts of diverse high quality food to meet energy requirements (Hofmann 1989), which is especially abundant in landscapes with high spatial heterogeneity in phenological stages. Indeed, we found higher variation (SD) in NDVI, as well as higher contingency (seasonality) in migrant summer niches. In contrast, overall NDVI was higher for resident niches. This likely reflects a higher prevalence of coniferous canopy cover at lower elevations in resident ranges, because NDVI is highest in forests compared to open (meadow) areas (Gamon et al. 1995). High values of NDVI in forested landscapes therefore do not necessarily reflect higher forage quality (Borowik et al. 2013) as the productivity of the canopy may not directly reflect the productivity of the accessible ground and shrub layers, especially for concentrate selecting species like roe deer. Because variation in NDVI was higher for migrants, likely due to migration to higher elevations with more diverse and less continuous cover types, we assume that overall forage heterogeneity was higher for migrants, allowing them to be more selective. In contrast, higher proportions of forest may provide increased shelter and protection for resident roe deer (Tablado et al. 2016), emphasizing the importance of the ratio of costs and benefits of migration. Interestingly, Tablado et al. (2016) found that roe deer concentrate their movement in fairly small areas selecting higher quality food and are able to forage optimally due to their solitary social system. Thus, if fine-scale forage diversity is sufficiently high in resident ranges, residency may be the more beneficial tactic for this small browser. If the cost of migration exceeds the benefits of migration, residency is expected to exceed migratory behavior (Fryxell and Holt 2013).

For northern ungulates, snow has been identified as the main driver for migration, especially for altitudinal migration (Mysterud 1999, Cagnacci et al. 2011). Our results support these findings and suggest that especially environmental niche factors that resemble increased seasonality and higher winter severity are main drivers for roe deer migration at the individual level. In particular, we found that migratory roe deer used steeper slopes in both seasonal ranges, stayed in more rugged terrain, and at higher elevations than resident roe deer during summer. We found that winter severity is an important discriminator between seasonal movement tactics (Fig. 6). Summer niches of migrants had the highest winter severity values, suggesting that migrants are forced to move to lower elevations to escape from limiting winter conditions.

Our niche-based approach also enabled us to test if migratory and resident individuals from partially migratory populations differ in their ecological conditions primarily in the allopatric season when the total range of the species expands (Fryxell and Sinclair 1988, Histøl and Hjeljord 1993, Hebblewhite and Merrill 2009, Jones et al. 2014), which is the breeding season (rut) for roe deer. Interestingly, we found that winter niches of migrants and residents were different also in the nonbreeding winter season, although to a lesser degree than during the migratory season in summer. This suggests that the niches of residents and migrants differ yearround. This niche separation may occur at different scales, which we were unable to assess, because we only used coarse-grained environmental niche variables. For example, Sanz-Aguilar et al. (2014) found more forage niche specialists among residents (72\%) than among migrants $(40 \%)$ on the shared range of migratory Storks (Ciconia ciconia), presumably because migrants may not be as familiar with the habitat. Similarly, Zini (2015) found that resident roe deer used higher quality forage habitat in summer than migratory roe deer would use if they stayed on the sympatric winter ranges, in one of our study areas (Italy-Rendena). With respect to predation risk exposure, Robinson et al. (2010) showed that elk with resident strategies were exposed to higher wolf (Canis lupus) predation risk at night compared to animals 
with migratory strategies on their shared winter range in a partially migratory population, presumably due to differential habituation to human activity. Overall, the result that migrant and resident roe deer do not share the same ecological niche, even in the season when the roe deer distribution range is smallest and their geographic ranges are in closest proximity, has important implications for understanding the ecology and management of large herbivores. If resident individuals are able to more effectively use winter ranges and avoid limiting conditions, for example by optimizing the use of feeding stations, we may expect changes in the relative costs and benefits of migration that may favor one strategy over another (Jones et al. 2014).

It remains to be tested if different movement tactics result in differences in demographic fitness under the paradigm of adaptability of migration (Avgar et al. 2013) and how biotic factors (density-dependence or predation) affect these relationships. Migratory roe deer may have lower fitness if seasonal niche switching pushes them toward the edge of their fundamental niche space or even into sinks (Hebblewhite et al. 2008). In contrast, residency could be the suboptimal tactic. For example, social fences (Mysterud et al. 2011) may constrain individuals from migrating, which may be forced to remain in less suitable niche conditions or resident animals may experience increased predation risk in environments with changing community structures due to carnivore recovery (Hebblewhite and Merrill 2009, Middleton et al. 2013). Essentially, there may be advantages to residency, and it is the balance of the costs and benefits that maintains partial migration over evolutionary timescales. While it is commonly assumed that migrants benefit from improved foraging conditions on allopatric ranges, there may be costs associated with migration due to increased mortality risk when passing through unknown regions and elevated energy requirements for migration (Hebblewhite et al. 2008, Middleton et al. 2013). Interestingly, we found that, out of the seven repeated animals we sampled, two switched between migration and residency between years, possibly due to such trade-offs.

In terms of risk, we were unable to test for differences between migrants and residents either through natural predation or hunting by humans. Habitat components that constitute a "safe" migratory destination may be diverse, scale-dependent and difficult to measure (White et al. 2014). For our populations, hunting by humans is the commonest mortality factor, but this risk is difficult to quantify and habitat components that constitute to a "safe" migratory destination may be manifold, scaledependent, and difficult to measure (White et al. 2014, Norum et al. 2015). We found summer niches of migrants to be the least correlated with the nightlights index, which cannot be over-interpreted, but may be suggestive that roe deer move away from human disturbance in summer. For example, Hewison et al. (2001) found that roe deer avoid areas with high associated levels of human activity and group size varied as a function of human density, possibly to decrease risk. Overall, niche switching implies that migratory behavior is a labile trait and allows flexibility in the face of environmental change (Boutin and Lane 2014), but future research should aim to incorporate fitness trade-offs to understand why both migration and resident tactics so commonly persist together (Bolger et al. 2008).

We found evidence that the combined spatiotemporal variation in forage, not just temporal variation, affected migration probability in roe deer. Spatial heterogeneity of resources may dampen the negative effects of abiotic (e.g., weather) and biotic (e.g., density) limiting factors on population growth (Wang et al. 2006). In agreement with Shaw and Couzin (2013) we found that low seasonality increases the proportion of residents and high seasonality increases the proportion of migrants. Although our findings match the expected predictions under the spatiotemporal resource hypothesis, our results should be considered cautiously with respect to scale-dependent relationships. In general, forage resource patches may be defined by their seasonality, quality, and size (Shaw and Couzin 2013), and we were only able to capture the first component well, and the second to a limited degree. Importantly though, we were not able to address the spatial configuration and resolution of forage resources in our different study areas. The probability of migration is also a function of resource distribution and migration is especially favored in seasonal environments with smaller habitat patches and little broad-scale variability (Müller and Fagan 2008, Müller et al. 2011). Our findings support this result, because migration probability was highest in diverse mountainous habitats in the Italian Alps and lowest in more homogenous, flat habitats in Koberg, Sweden. Animal movement distances (van Moorter et al. 2013), and more specifically migration distances (Teitelbaum et al. 2015) have also been suggested to be a function of the scale of landscape variability. Also in our study, migratory roe deer moved furthest in Norway, where broad-scale landscape variability is much higher than in our alpine Italian study sites, which confirms that the correlation between geographic, and ED is a function of landscape heterogeneity. Although distance in space is generally a good descriptor of variation along ecological gradients, this relationship is dependent on spatiotemporal scales of variability (Teitelbaum et al. 2015; Appendix S3: Fig. S1).

Which factor is more dominant in shaping and maintaining migratory behavior at the individual level is likely to be a function of density dependence at the level of the population (Fryxell and Sinclair 1988). In fact, the role of density in regulating partially migratory populations is well known in conceptual models and the bird literature (Kaitala et al. 1993). Partial migration is expected to be maintained in stochastic environments where density dependence is present (Lundberg 1988), but to date only very few quantitative studies have tested these relationships (Mysterud et al. 2011). For example, Eggeman et al. (2016) showed that Cervus spp. migration increased with 
population density, consistent with the competition avoidance hypothesis. In our study, increased levels of spatial variation in seasonal vegetation, which was highest in the Italian study area in the Alps (ItalyRendena; Fig. 3), along with high densities favosred migration in the studied roe deer populations (Fig. 7). However, further tests with broader ranges of densities and accounting for habitat-quality may be needed to evaluate density dependence as the potential mechanism to regulate relative benefits of migration vs. residency. For example, high densities may prohibit migration if the surrounding habitat is already occupied and migratory behavior is inhibited due to social fences (Mysterud et al. 2011). Such relationships may also very temporally throughout the year (Leo et al. 2009). Furthermore, the dynamics of territoriality, which is applicable to roe deer males, may by very important in shaping patterns of facultative switching in partially migratory populations (Kokko 2011). Thus, besides forage benefits, the unique roe deer mating system may also be an important limiting resource. Overall, ungulates commonly have to make trade-off decisions between staying out of low-elevation winter ranges with potentially higher interspecific competition and the risk of being exposed to adverse winter conditions when staying at high elevation summer ranges. The relative advantages of access to prolonged forage quality and/or reproduction by occupying better territories must outweigh the cost of migration and combining the two seasonal niches must come at an extra gain in fitness to maintain migration as a tactic. Species with high diversity in migratory movements that can alter their behavior in response to environmental or demographic factors have been shown to be less vulnerable to anthropogenic change (Gilroy et al. 2016).

\section{Conclusion}

The ecological niche concept provides an underutilized framework for outlining questions surrounding the patterns and the determinants underlying migration across species (Jonzén et al. 2011). Future changes including climate change and anthropogenic landscape alteration will affect the niches of migrants, residents and all movement tactics that lie between these two endpoints of the continuum. Behavioral plasticity seems to allow individuals to adjust to changing environmental conditions and we have shown that while resident roe deer remain stable in largely static niche conditions year-round, roe deer are plastic in switching seasonal niches when migrating. Thus, it appears that migratory behavior in roe deer is labile, allowing them to thrive under changing conditions (within certain limits). Here we provided a first example studying roe deer, but relationships between seasonal movement strategies and plasticity in realized seasonal niches remains to be tested for other ungulate species and for time-variant niche conditions. Understanding the functional importance of key components of spatiotemporal niche variability will offer insights into linking predicted future resource dynamics to movement behaviors.

\section{AcKnowledgments}

This paper was conceived and written within the collaborative EURODEER project (paper no. 006 of the EURODEER series; www.eurodeer.org). The co-authors are grateful to all members for their support for the initiative. The EURODEER spatial database is hosted by Fondazione Edmund Mach. The GPS data collection of the Fondazione Edmund Mach was supported by the Autonomous Province of Trento under grant number 3479 to FC (BECOCERWI-Behavioural Ecology of Cervids in Relation to Wildlife Infections). W. Peters and F. Cagnacci thank the Wildlife and Forest Service of the Autonomous Province of Trento and the Hunting Association of Trento Province (ACT) for support and help during captures. Financial support for GPS data collection in the Bavarian Forest was provided by the EU-program INTERREG IV (EFRE Ziel 3) and the Bavarian Forest National Park Administration. The Swedish study was supported by grants from the private foundation of "Marie Claire Cronstedts Minne," the Swedish Environmental Protection Agency, and the Swedish Association for Hunting and Wildlife Management. The Norwegian data collection was funded by the Norwegian Environment Agency and the county administration of Buskerud county. J. Linnell was also funded by the Research Council of Norway (grant 251112). A. Mysterud and W. Peters greatly acknowledge the support of the Centre for Advanced Study in Oslo, Norway that funded and hosted the research project ("Climate effects on harvested large mammal populations") during the academic year of 2015-2016. Funding was also provided by the University of Montana and NASA grant number NNX11AO47G to M. Hebblewhite. We thank Joel Berger, Scott L. Mills, Cynthia Hartway, Kamran Safi, and two anonymous reviewers for helpful comments on earlier drafts of this manuscript.

\section{Literature Cited}

Albon, S. D., and R. Langvatn. 1992. Plant phenology and the benefits of migration in a temperate ungulate. Oikos 65: 502-513.

Arnold, T. W. 2010. Uninformative parameters and model selection using Akaike's information criterion. Journal of Wildlife Management 74:1175-1178.

Avgar, T., G. Street, and J. M. Fryxell. 2013. On the adaptive benefits of mammal migration. Canadian Journal of Zoology 92:481-490.

Ball, J. P., C. Nordengren, and K. Wallin. 2001. Partial migration by large ungulates: characteristics of seasonal moose Alces alces ranges in northern Sweden. Wildlife Biology 7: 39-47.

Barnowe-Meyer, K. K., P. J. White, L. P. Waits, and J. A. Byers. 2013. Social and genetic structure associated with migration in pronghorn. Biological Conservation 168: 108-115.

Bergman, M. C., A. J. Schaefer, and N. S. Luttich. 2000. Caribou movement as a correlated random walk. Oecologia 123:364-374.

Bischof, R., L. E. Loe, E. L. Meisingset, B. Zimmermann, B. Van Moorter, and A. Mysterud. 2012. A migratory northern ungulate in the pursuit of spring: Jumping or surfing the green wave? American Naturalist 180:407-424.

Bolger, D. T., W. D. Newmark, T. A. Morrison, and D. F. Doak. 2008. The need for integrative approaches to understand and conserve migratory ungulates. Ecology Letters 11: 63-77. 
Borowik, T., N. Pettorelli, L. Sönnichsen, and B. Jędrzejewska. 2013. Normalized Difference Vegetation Index (NDVI) as a predictor of forage availability for ungulates in forest and field habitats. European Journal of Wildlife Research 59: 675-682.

Boutin, S., and J. E. Lane. 2014. Climate change and mammals: evolutionary versus plastic responses. Evolutionary Applications 7:29-41.

Boyle, W. A. 2011. Short-distance partial migration of Neotropical birds: a community-level test of the foraging limitation hypothesis. Oikos 120:1803-1816.

Broennimann, O., et al. 2012. Measuring ecological niche overlap from occurrence and spatial environmental data. Global Ecology and Biogeography 21:481-497.

Bunnefeld, N., L. Börger, B. van Moorter, C. M. Rolandsen, H. Dettki, E. J. Solberg, and G. Ericsson. 2011. A modeldriven approach to quantify migration patterns: individual, regional and yearly differences. Journal of Animal Ecology 80:466-476.

Burnham, K. P., and D. R. Anderson. 2002. Model selection and multimodel inference: a practical information-theoretic approach. Springer-Verlag, New York, New York, USA.

Burnham, K. P., and D. R. Anderson. 2004. Multimodel inference - understanding AIC and BIC in model selection. Sociological Methods and Research 33:261-304.

Börger, L., and L. M. Fryxell. 2012. Quantifying individual differences in dispersal using net squared displacement. Pages 222-230 in J. Clobert, M. Baguette, T. Benton, and J. Bullock, editors. Dispersal and spatial evolutionary ecology. Oxford University Press, Oxford, UK.

Cagnacci, F., et al. 2011. Partial migration in roe deer: migratory and resident tactics are end points of a behavioural gradient determined by ecological factors. Oikos 120:1790-1802.

Cagnacci, F., et al. 2016. How many routes lead to migration? Comparison of methods to assess and characterize migratory movements. Journal of Animal Ecology 85:54-68.

Chapman, B. B., C. Bronmark, J. A. Nilsson, and L. A. Hansson. 2011a. The ecology and evolution of partial migration. Oikos 120:1764-1775.

Chapman, B. B., K. Hulthen, D. R. Blomqvist, L. A. Hansson, J. A. Nilsson, J. Brodersen, P. A. Nilsson, C. Skov, and C. Bronmark. 2011b. To boldly go: individual differences in boldness influence migratory tendency. Ecology Letters 14: 871-876.

Chessel, D., A. B. Dufour, and J. Thioulouse. 2004. The ade4 package - I: one-table methods. R News 4:5-10.

Cohen, J. 1960. A coefficient of agreement for nominal scales. Educational and Psychological Measurements 20:37-46.

Colwell, R. K. 1974. Predictability, constancy, and contingency of periodic phenomena. Ecology 55:1148-1153.

Dingle, H. 1996. Migration. The biology of life on the move. Oxford University Press, Oxford, UK.

Dingle, H., and V. A. Drake. 2007. What is migration? BioScience 57:113-121.

Doledec, S., and D. Chessel. 1987. Rythmes saisonniers et composantes stationnelles en milieu aquatique. I. Description d'un plan d'observations complet par projection de variables. Acta Oecologica, Oecologia Generalis 8:403-426.

Edwards, R. Y., and R. W. Ritcey. 1956. The migrations of a moose herd. Journal of Mammalogy 37:486-494.

Eggeman, S., M. Hebblewhite, H. Bohm, J. Whittington, and E. Merrill. 2016. Behavioral flexibility in migratory behavior in a long-lived large herbivore. Journal of Animal Ecology 85:785-797.

English, A. K., A. L. Chauvenet, K. Safi, and N. Pettorelli. 2012. Reassessing the determinants of breeding synchrony in ungulates. PLoS ONE 7:0041444.
Fieberg, J., and C. O. Kochanny. 2005. Quantifying homerange overlap: the importance of the utilization distribution. Journal of Wildlife Management 69:1346-1359.

Fieberg, J., D. W. Kuehn, and G. D. DelGiudice. 2008. Understanding variation in autumn migration of northern white-tailed deer by long-term study. Journal of Mammalogy 89:1529-1539.

Folstad, I., A. C. Nilssen, O. Halvorsen, and J. Andersen. 1991. Parasite avoidance: the cause of post-calving migrations in Rangifer? Canadian Journal of Zoology 69:2423-2429.

Fryxell, J. M. 1991. Forage quality and aggregation by large herbivores. American Naturalist 138:478-498.

Fryxell, J. M., and R. D. Holt. 2013. Environmental change and the evolution of migration. Ecology 94:1274-1279.

Fryxell, J. M., and A. R. E. Sinclair. 1988. Causes and consequences of migration by large herbivores. Trends in Ecology and Evolution 3:237-241.

Fryxell, J. M., J. F. Wilmshurst, and A. R. E. Sinclair. 2004. Predictive models of movement by Serengeti grazers. Ecology 85:2429-2435.

Gaidet, N., and P. Lecomte. 2013. Benefits of migration in a partially-migratory tropical ungulate. BMC Ecology 13: $13-36$.

Gamon, J. A., C. B. Field, M. L. Goulden, K. L. Griffin, A. E. Hartley, G. Joel, J. Penuelas, and R. Valentini. 1995. Relationships between NDVI, canopy structure, and photosynthesis in three Californian vegetation types. Ecological Applications 5:28-41.

Gaudry, W., S. Saïd, J.-M. Gaillard, T. Chevrier, A. Loison, D. Maillard, and C. Bonenfant. 2015. Partial migration or just habitat selection? Seasonal movements of roe deer in an Alpine population. Journal of Mammalogy 96:502-510.

Gilroy, J. J., J. A. Gill, S. H. M. Butchart, V. R. Jones, and A. M. A. Franco. 2016. Migratory diversity predicts population declines in birds. Ecology Letters 19:308-317.

Gómez, C., E. A. Tenorio, P. Montoya, and C. D. Cadena. 2016. Niche-tracking migrants and niche-switching residents: evolution of climatic niches in New World warblers (Parulidae). Proceedings of the Royal Society B 283: 20152458.

Gordon, I. J., A. J. Hester, and M. Festa-Bianchet. 2004. Review: the management of wild large herbivores to meet economic, conservation and environmental objectives. Journal of Applied Ecology 41:1021-1031.

Gower, J. C. 1971. A general coefficient of similarity and some of its properties. Biometrics 27:857-874.

Grayson, K. L., and H. M. Wilbur. 2009. Sex- and contextdependent migration in a pond-breeding amphibian. Ecology 90:306-312.

Grosbois, V., O. Gimenez, J. M. Gaillard, R. Pradel, C. Barbraud, J. Clobert, A. P. Møller, and H. Weimerskirch. 2008. Assessing the impact of climate variation on survival in vertebrate populations. Biological Reviews 83:357-399.

Grovenburg, T. W., C. N. Jacques, R. W. Klaver, C. S. DePerno, T. J. Brinkman, C. C. Swanson, and J. A. Jenks. 2011. Influence of landscape characteristics on migration strategies of white-tailed deer. Journal of Mammalogy 92: 534-543.

Hall, D. K., G. A. Riggs, and V. V. Salomonson. 2000. MODIS/ Terra snow cover 8-day L3. Global $500 \mathrm{~m}$ Grid V03, February 2000 to February 2002. National Snow and Ice Data Center, Digital Media. Boulder, Colorado, USA.

Hansen, M. C., et al. 2013. High-resolution global maps of 21stcentury forest cover change. Science $342: 850-853$.

Hebblewhite, M., and E. H. Merrill. 2009. Trade-offs between wolf predation risk and forage at multiple spatial scales in a partially migratory ungulate. Ecology 26:54-59. 
Hebblewhite, M., E. Merrill, and G. McDermid. 2008. A multiscale test of the forage maturation hypothesis in a partially migratory ungulate population. Ecological Monographs 78: 141-166.

Hein, A. M., C. Hou, and J. F. Gillooly. 2012. Energetic and biomechanical constraints on animal migration distance. Ecology Letters 15:105-110.

Hewison, A. J. M., J.-P. Vincent, and D. Reby. 1998. Social organisation of European roe deer. Pages 189-219 in R. Andersen, P. Duncan, and J. D. C. Linnell, editors. The European roe deer: the biology of success. Scandinavian University Press, Oslo, Norway.

Hewison, A. J., J. P. Vincent, J. Joachim, J. M. Angibault, B. Cargnelutti, and C. Cibien. 2001. The effects of woodland fragmentation and human activity on roe deer distribution in agricultural landscapes. Canadian Journal of Zoology 79: 679-689.

Hijmans, R. J., S. E. Cameron, J. L. Parra, P. G. Jones, and A. Jarvis. 2005. Very high resolution interpolated climate surfaces for global land areas. International Journal of Climatology 25:1965-1978.

Hirano, A., R. Welch, and H. Lang. 2003. Mapping from ASTER stereo image data: DEM validation and accuracy assessment. ISPRS Journal of Photogrammetry and Remote Sensing 57:356-370.

Hirzel, A. H., and G. Le Lay. 2008. Habitat suitability modelling and niche theory. Journal of Applied Ecology 45: 1372-1381.

Histøl, T., and O. Hjeljord. 1993. Winter feeding strategies of migrating and nonmigrating moose. Canadian Journal of Zoology 71:1421-1428.

Hobbs, N. T. 1996. Modification of ecosystems by ungulates. Journal of Wildlife Management 60:695-713.

Hofmann, R. R. 1989. Evolutionary steps of ecophysiological adaptation and diversification of ruminants - a comparative view of their digestive-system. Oecologia 78:443-457.

Hopcraft, J. G. C., J. Morales, H. Beyer, M. Borner, E. Mwangomo, A. Sinclair, H. Olff, and D. T. Haydon. 2014. Competition, predation, and migration: individual choice patterns of Serengeti migrants captured by hierarchical models. Ecological Monographs 84:355-372.

Hosmer, D. W., and S. Lemeshow, editors. 2000. Applied logistic regression. John Wiley and Sons, New York, New York, USA.

Huete, A., K. Didan, T. Miura, E. P. Rodriguez, X. Gao, and L. G. Ferreira. 2002. Overview of the radiometric and biophysical performance of the MODIS vegetation indices. Remote Sensing of Environment 83:195-213.

Hutchinson, G. E. 1957. Concluding remarks. Cold Spring Harbor Symposium on Quantitative Biology 22(2): 415-427.

Jarvis, A., H. I. Reuter, A. Nelson, and E. Guevara. 2008. Holefilled SRTM for the globe Version 4. CGIAR-CSI SRTM $90 \mathrm{~m}$ Database. http://srtm.csi.cgiar.org

Johnson, D. H. 1980. The comparison of usage and availability measurements for evaluating resource preference. Ecology 61:65-71.

Jones, J. D., M. J. Kauffman, K. L. Monteith, B. M. Scurlock, S. E. Albeke, and P. C. Cross. 2014. Supplemental feeding alters migration of a temperate ungulate. Ecological Applications 24:1769-1779.

Jongman, R. H. G., C. J. F. Ter Braak, and O. F. R. Van Tongeren. 1995. Data analysis in community and landscape ecology. Cambridge University Press, Cambridge, UK.

Jonzén, N., E. Knudsen, R. Holt, and B. Sæther. 2011. Uncertainty and predictability: the niches of migrants and nomads. Pages 91-109 in E. J. Milner-Gulland, J. Fryxell, and A. R. E. Sinclair, editors. Animal migration: a synthesis. Oxford University Press, Oxford, UK.

Kaitala, A., V. Kaitala, and P. Lundberg. 1993. A theory of partial migration. American Naturalist 142:59-81.

Kerr, L. A., D. H. Secor, and P. M. Piccoli. 2009. Partial migration of fishes as exemplified by the estuarine-dependent white perch. Fisheries 34:114-123.

Kokko, H. 2011. Directions in modelling partial migration: How adaptation can cause a population decline and why the rules of territory acquisition matter. Oikos 120:1826-1837.

Lack, D. 1943. The problem of partial migration. British Birds 37:122-130.

Laube, I., C. H. Graham, and K. Böhning-Gaese. 2015. Niche availability in space and time: migration in Sylvia warblers. Journal of Biogeography 42:1896-1906.

LeResche, R. E. 1974. Moose migrations in North America. Naturaliste Canadien 101:393-415.

Linnell, J. D. C., P. Duncan, and R. Andersen. 1998. The European roe deer: a portrait of a successful species. Pages 11-22 in R. Andersen, P. Duncan, and J. D. C. Linnell, editors. The European roe deer: the biology of success. Scandinavian University Press, Oslo, Norway.

Loe, L. E., A. Mysterud, V. Veiberg, and R. Langvatn. 2009. Negative density-dependent emigration of males in an increasing red deer population. Proceedings of the Royal Society B 276:2581-2587.

Lone, K., L. E. Loe, T. Gobakken, J. D. C. Linnell, J. Odden, J. Remmen, and A. Mysterud. 2014. Living and dying in a multi-predator landscape of fear: roe deer are squeezed by contrasting pattern of predation risk imposed by lynx and humans. Oikos 123:641-651.

Lundberg, P. 1988. The evolution of partial migration in birds. Trends in Ecology and Evolution 3:172-175.

Maechler, M., P. Rousseeuw, A. Struyf, M. Hubert, and K. Hornik. 2015. Cluster: Cluster analysis basics and extensions. R package version 2.0.1. https://cran.r-project.org/web/ packages/cluster/index.html

Mancinelli, S., W. Peters, L. Boitaini, M. Hebblewhite, and F. Cagnacci. 2015. Roe deer summer habitat selection at multiple spatio-temporal scales in an Alpine environment. Hystrix-Italian Journal of Mammalogy 26:132-140.

Maselli, F. 2004. Monitoring forest conditions in a protected Mediterranean coastal area by the analysis of multiyear NDVI data. Remote Sensing of Environment 89:423-433.

McClintock, B. T., R. King, L. Thomas, J. Matthiopoulos, B. J. McConnell, and J. M. Morales. 2012. A general discrete-time modeling framework for animal movement using multistate random walks. Ecological Monographs 82:335-349.

Melis, C., et al. 2009. Predation has a greater impact in less productive environments: variation in roe deer, Capreolus capreolus, population density across Europe. Global Ecology and Biogeography 18:724-734.

Middleton, A. D., M. J. Kauffman, D. E. McWhirter, J. G. Cook, R. C. Cook, A. A. Nelson, M. D. Jimenez, and R. W. Klaver. 2013. Animal migration amid shifting patterns of phenology and predation: lessons from a Yellowstone elk herd. Ecology 94:1245-1256.

Monserud, R. A., and R. Leemans. 1992. Comparing global vegetation maps with the Kappa statistic. Ecological Modelling 62:275-293.

Morellet, N., et al. 2013. Seasonality, weather and climate affect home range size in roe deer across a wide latitudinal gradient within Europe. Journal of Animal Ecology 82: 1326-1339.

Müller, T., and W. F. Fagan. 2008. Search and navigation in dynamic environments from individual behaviors to population distributions. Oikos 117:654-664. 
Müller, T., et al. 2011. How landscape dynamics link individualto population-level movement patterns: a multispecies comparison of ungulate relocation data. Global Ecology and Biogeography 20:683-694.

Mysterud, A. 1999. Seasonal migration pattern and home range of roe deer (Capreolus capreolus) in an altitudinal gradient in southern Norway. Journal of Zoology 247:479-486.

Mysterud, A., and E. Ostbye. 1995. Bed-site selection by European roe deer (Capreolus capreolus) in southern Norway during winter. Canadian Journal of Zoology 73:924-932.

Mysterud, A., L. E. Loe, B. Zimmermann, R. Bischof, V. Veiberg, and E. Meisingset. 2011. Partial migration in expanding red deer populations at northern latitudes - a role for density dependence? Oikos 120:1817-1825.

Mysterud, A., L. Qviller, E. L. Meisingset, and H. Viljugrein. 2016. Parasite load and seasonal migration in red deer. Oecologia 180:401-407.

Naidoo, R., P. Du Preez, G. Stuart-Hill, M. Jago, and M. Wegmann. 2012. Home on the range: factors explaining partial migration of African buffalo in a tropical environment. PLoS ONE 7:0036527.

Nakazawa, Y., A. T. Peterson, E. Martínez-Meyer, and A. G. Navarro-Sigüenza. 2004. Seasonal niches of nearcticneotropical migratory birds: implications for the evolution of migration. Auk 121:610-618.

Nelson, M. E. 1995. Winter range arrival and departure of white-tailed deer in northeastern Minnesota. Canadian Journal of Zoology 73:1069-1076.

Nicholson, M. C., R. T. Bowyer, and J. G. Kie. 1997. Habitat selection and survival of mule deer: tradeoffs associated with migration. Journal of Mammalogy 78:483-504.

Norum, J. K., K. Lone, J. D. C. Linnell, J. Odden, L. E. Loe, and A. Mysterud. 2015. Landscape of risk to roe deer imposed by lynx and different human hunting tactics. European Journal of Wildlife Research 61:831-840.

Olsson, I. C., L. A. Greenberg, E. Bergman, and K. Wysujack. 2006. Environmentally induced migration: the importance of food. Ecology Letters 9:645-651.

Peterson, M. N., R. R. Lopez, P. A. Frank, M. J. Peterson, and N. J. Silvy. 2003. Evaluating capture methods for urban white-tailed deer. Wildlife Society Bulletin 31:1176-1187.

Pulliam, H. R. 2000. On the relationship between niche and distribution. Ecology Letters 3:349-361.

R Development Core Team. 2013. R: a language and environment for statistical computing. R Foundation for Statistical Computing, Vienna, Austria. www.r-project.org

Ramanzin, M., E. Sturaro, and D. Zanon. 2007. Seasonal migration and home range of roe deer (Capreolus capreolus) in the Italian eastern Alps. Canadian Journal of Zoology 85:280-289.

Reitan, O. 1988. A cliff as part of mammal habitats in woodland. Viltrevy 13:3-28.

Robinson, B. W., M. Hebblewhite, and E. H. Merrill. 2010. Are migrant and resident elk (Cervus elaphus) exposed to similar forage and predation risk on their sympatric winter range? Oecologia 164:265-275.

Rolandsen, C. M., E. J. Solberg, B.-E. Sæther, B. V. Moorter, I. Herfindal, and K. Bjørneraas. 2016. On fitness and partial migration in a large herbivore - migratory moose have higher reproductive performance than residents. Oikos.

Rousseeuw, P. J. 1987. Silhouettes: a graphical aid to the interpretation and validation of cluster analysis. Journal of Computational and Applied Mathematics 20:53-65.

Sabine, D. L., S. F. Morrison, H. A. Whitlaw, W. B. Ballard, G. J. Forbes, and J. Bowman. 2002. Migration behavior of white-tailed deer under varying winter climate regimes in
New Brunswick. Journal of Wildlife Management 66: $718-728$

Sanz-Aguilar, A., R. Jovani, C. J. Melián, R. Pradel, and J. L. Tella. 2014. Multi-event capture-recapture analysis reveals individual foraging specialization in a generalist species. Ecology 96:1650-1660.

Sawyer, H., and M. J. Kauffman. 2011. Stopover ecology of a migratory ungulate. Journal of Animal Ecology 80: 1078-1087.

Schoener, T. W. 1974. Resource partitioning in ecological communities. Science 185:27-39.

Senft, R. L., M. B. Coughenour, D. W. Bailey, L. R. Rittenhouse, O. E. Sala, and D. M. Swift. 1987. Large herbivore foraging and ecological hierarchies. BioScience 37:789-795; 798-799.

Shaw, A. K., and I. D. Couzin. 2013. Migration or residency? The evolution of movement behavior and information usage in seasonal environments. American Naturalist 181:114-124.

Sih, A., J. Cote, M. Evans, S. Fogarty, and J. Pruitt. 2012. Ecological implications of behavioural syndromes. Ecology Letters 15:278-289.

Silverman, B. W. 1986. Density estimation for statistics and data analysis. Chapman and Hall, London, UK.

Singh, N. J., L. Borger, H. Dettki, N. Bunnefeld, and G. Ericsson. 2012. From migration to nomadism: movement variability in a northern ungulate across its latitudinal range. Ecological Applications 22:2007-2020.

Small, C., F. Pozzi, and C. D. Elvidge. 2005. Spatial analysis of global urban extent from DMSP-OLS night lights. Remote Sensing of Environment 96:277-291.

Soberón, J. 2007. Grinnellian and Eltonian niches and geographic distributions of species. Ecology Letters 10: $1115-1123$.

Soberón, J., and M. Nakamura. 2009. Niches and distributional areas: concepts, methods, and assumptions. Proceedings of the National Academy of Sciences USA 106: 19644-19650.

Southwood, T. R. E. 1962. Migration of terrestrial arthropods in relation to habitat. Biological Reviews 37:171-211.

Spitz, D. 2015. Does migration matter? Causes and consequences of migratory behavior in Sierra Nevada bighorn heep. Dissertation. University of Montana, Missoula, Montana, USA.

Spitz, D. B., M. Hebblewhite, and T. R. Stephenson. 2016. 'MigrateR': extending model-driven methods for classifying and quantifying animal movement behavior. Ecography.

Tablado, Z., E. Revilla, D. Dubray, S. Saïd, D. Maillard, and A. Loison. 2016. From steps to home range formation: species-specific movement upscaling among sympatric ungulates. Functional Ecology 30:1384-1396.

Taylor, C. M., and D. R. Norris. 2007. Predicting conditions for migration: effects of density dependence and habitat quality. Biology Letters 3:280-283.

Taylor, L. R., and R. A. J. Taylor. 1977. Aggregation, migration and population mechanics. Nature 265:415-421.

Teitelbaum, C. S., W. F. Fagan, C. H. Fleming, G. Dressler, J. M. Calabrese, P. Leimgruber, and T. Mueller. 2015. How far to go? Determinants of migration distance in land mammals. Ecology Letters 18:545-552.

ter Braak, C., editor. 1992. Permutation versus bootstrap significance tests in multiple regression and ANOVA. SpringerVerlag, Berlin, Germany.

Terrill, S. B., and K. P. Able. 1988. Bird migration terminology. Auk 105:205-206.

Turchin, P. 1998. Quantitative analysis of movement: measuring and modeling population redistribution in plants and animals. Sinauer Associates, Sunderland, Massachusetts, USA. 
van Moorter, B., N. Bunnefeld, M. Panzacchi, C. M. Rolandsen, E. J. Solberg, and B. E. Saether. 2013. Understanding scales of movement: animals ride waves and ripples of environmental change. Journal of Animal Ecology 82:770-780.

Van Soest, P. J. 1983. Nutritional ecology of the ruminant. Cornell University Press, Ithaca, New York, USA.

Wahlström, L. K., and O. Liberg. 1995. Patterns of dispersal and seasonal migration in roe deer (Capreolus capreolus). Journal of Zoology 235:455-467.

Walker, D. A., J. C. Halfpenny, M. D. Walker, and C. A. Wessman. 1993. Long-term studies of snow-vegetation interactions. BioScience 43:287-301.

Wang, G., N. T. Hobbs, R. B. Boone, A. W. Illius, I. J. Gordon, J. E. Gross, and K. L. Hamlin. 2006. Spatial and temporal variability modify density dependence in populations of large herbivores. Ecology 87:95-102.

White, P. J., T. L. Davis, K. K. Barnowe-Meyer, R. L. Crabtree, and R. A. Garrott. 2007. Partial migration and philopatry of Yellowstone pronghorn. Biological Conservation 135:502-510.

White, K. S., N. L. Barten, S. Crouse, and J. Crouse. 2014. Benefits of migration in relation to nutritional condition and predation risk in a partially migratory moose population. Ecology 95:225-237.

Wiens, J. A. 1989. Spatial scaling in ecology. Functional Ecology 3:385-397.

Zini, V. 2015. Tattiche di movimento contrastanti e differenze nell'utilizzo dell'habitat del capriolo (Capreolus capreolus) a livello stagionale in ambiente alpino. Univerity of Rome - La Sapienza, Rome, Italy.

\section{SUPPORTING INFORMATION}

Additional supporting information may be found in the online version of this article at http://onlinelibrary.wiley.com/ doi/10.1002/ecm.1250/full

\section{Data Availability}

Data associated with this paper are available from the Dryad Digital Repository: https://doi.org/10.5061/dryad.95930 